أسباب التجاوزعلى عقارات الدولة ومخحاطرها ( دراسـة تحليلية وصفية )

ريسكان فرحسان صـالح قسم القانون، كلية العلوم الإنسانية والاجتماعية، جامعاة كويه، كويه، إقليم كردستان، العراق. البريد الاليكتروني: Rekan.farhan@koyauniversity.org

$$
\text { ريباز اردلان بكر }
$$

قسم القانون، كلية العلوم الإنسانية والاجتماعية، جامعة كويه، كويه، إقليم كردستان، العراق. rebaz.alhawezy@koyauniversity.org البريد الاليكتروني:

الملتخص:

إنّ ظاهرة التجاوزات على عقارات الدولة تجاوزت كل التوقعات، وذلك لزيادتها لأسباب سياسية وقانونية واقتصادية واجتماعية، إذ لم تسلم عقارات الدولة من التجاوز علهها في الآونة الأخيرة، وقد شكل التجاوز أنماطا مختلفة، تمثل الدافع منها وفق وضعية مصالح المتجاوزين، الأمر الذي ترتب عليه في الوقت الراهن وعلى وجه الخصوص بعد سقوط النظام البعثي البائد استباحة ممتلكات الدولة، لعدم

$$
\text { وجود رادع قوي لها. }
$$

فعلى الرغم من صدور قوانين وقرارات صارمة تجرّم وتحرّم التجاوز على عقارات الدولة، ومع وجود السلطتين التنفيذية والقضائية المعنيتين بتطبيقها وتنفيذها، إلا إنّ ظاهرة التجاوز في صعود مستمر، الأمر الذي نتج عنه سلبيات عديدة، بمستويات كثيرة، وأهمها إهدار المال العام، وعدم الإمتثال للقانون واحترامه، وكذلك التغيير الديموغرافي للمدن.

تناول البحث هذه المسائل كمحاولة للمساهمة في عرض مشكلة التجاوزات، وإبداء الحلول لها، ولإحاطة بجوانب البحث، تم تقسيم الدراسة إلى مبحثين، نتطرق في المبحث الأول لماهية التجاوز على عقارات الدولة، أما المبحث الثاني فنخصصهاه للحديث عن أسباب التجاوز على عقارات الدولة، كما نختم البحث بذكر أهم الاستنتاجات والتوصيات. الكلمات المفتاحية: التجاوز، عقارات، أسباب. 


\section{أولا/ التعريف بموضهوع البحث:}

قد يحدث أنْ يتجاوز الأفراد على عقارات الدولة بالاعتداء بصورة أو بأخرى، مما يتطلب تدخل الدولة بإحاطتها بالحماية اللازمة لمنع التجاوز إبتداءً أو برفع التجاوز عنها، وذلك عن طريق سنّ القوانين وإصدار القرارات، لذلك تعد مشكلة وظاهرة التجاوز على عقارات الدولة أحد أبرز الأزمات التي يعاني منها المواطن العراقي، فتعد التجاوزات من مظاهر المخالفة البارزة، كما أنهّا انتهاك صريح لحرمة النظام وهيبة القانون السائد، فالمتجاوزون خرقوا القانون بوضح النهار دون شعور بالمسؤولية ولا ردع رسمي، ويرتبط كل ذلك بالفساد والعلاقات الإجتماعية بين المتجاوزين والمسؤولين، وذلك أحد إفرازات ضعف الدولة وسوء إدارتها، الذي نجم عنه ضعف في تطبيق نصوص الحماية القانونية المشرعة للحفاظ على عقارات الدولة، وأيضا بعض النصوص أدّى الى اهدار اموال الدولة. إنّ التجاوز على عقارات الدولة من المشاكل الضاربة في القدم، والتي تعاني منها الحكومات باستمرار، إذ تعاني العديد من المدن العراقية ومنها مدن إقليم كوردستان من تنامي ظاهرة التجاوزات والتي باتت تهدد بكارثة بيئية، إذا ما أستمر الحال على ما هو عليه دون وضيع حلول سريعة وجذرية لحل مشكلات سكاهها بتوفير احتياجاتهم من وحدات سكنية وفرص اقتصادية، إذ تعد التجاوزات العشوائية إحدى الحلول الذاتية التي يلجأ إلهها المواطنون لتوفير احتياجاتهم من مسكن أو فرص عمل، إذ تظافرت مجموعة من العوامل دفتههم مجبرين في أحوال

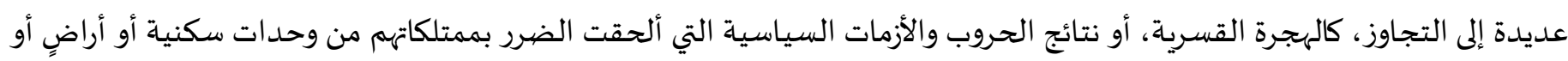
محلات تجارية، وعدم فاعلية السياسات الإسكانية في حل أزمة السكن، وغياب الدولة في توفير فرص اقتصادية لمواطنيها، علما بأنّ معظم المتجاوزين على عقارات الدولة هم من المتنفذين والجماعات الخارجة عن القانون وبعض من الأحزاب السياسياة، إذ أنّ قضية التجاوز على عقارات الدولة في المدن العراقية أزمة عامة ليست منحصرةً بأفرادٍ استغلوا ضعف سلطة القانون، بل إنّا تمتد لتشمل أفرادا يمثلون سلطة القانون، وتنظيمات وأحزاب سياسية تنتمي إلى الدولة العراقية القائمة. ويُشكل موضوع التجاوز على عقارات الدولة أهمية كبيرة في وقتنا الحالي، إذ يلحظ تزايده بشكل كبير، وأصبحت التجاوزات بمختلف أنواعها ظاهرة لا تخلو منها أي مدينة في العراق، ومنها مدن إقليم كوردستان وباتت تشكل عائقا أمام تقديم الخدمات البلدية للمواطنين. إنّ الإدارة في العراق الحالي عاجزة عن إزالة التجاوزات لأسباب عدة منها كونها ليست إدارة حازمة وحكيمة، فضهلا عن كونها مناطقية، يديرها أشخاص من أهالي المنطقة، ووجودهم قائم على صوت الناخب الذي سيعاتبه بشدة حين إزالة تجاوزه، وبذا أصبحت الإدارة ضعيفة،

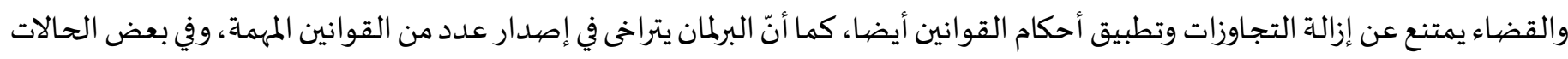
يصدر القوانين التي تؤدي إلى إهدار أموال الدولة، وتقنين الفساد، لذا تتحمل السلطات الثلاث (التشريعية والتنفيذية والقضائية) مسؤولية ضياع أملاك الدولة، ولاسيما أنّ معظم المتجاوزين لا يدفعهم عنصر الحاجة الماسة، بينما يبقى الشخص الذي يرغب بتطبيق القانون والعد الة خاسرا، وكأنّ الأمر يعد مكافأة لمن يخرق القانون. 
تعد دراسة التجاوزات على عقارات الدولة من المشاكل التي لا تخفى أهميتها، إذ لم تتناول بشكل أكاديمي، لتوضيح هذه الظاهرة وأبعادها المكانية. وتكمن أهمية هذه الدراسة في أهها محاولة لمعالجة ظاهرة التجاوز على عقارات الدولة، التي هي في توسع مستمر ، مما يهدد بابتلاع أجزاء كبيرة من أراضي الدولة، ومع ذلك فإنّ هذا البحث محاولة لإبراز خطورة ظاهرة التجاوز على عقارات الدولة؛ لأنّ العقارات لها أهمية اقتصادية في رفد الموازنة الحكومية بالأموال اللازمة بشكل يخفف من حجم الاتكال المفرط على الواردات النفطية التي أغرقت العراق في النهج الريعي. وتكمن أهمية هذه الدراسة في أهها محاولة لبيان ضرورة تدخل القانون في معالجاة الاعتداءات والانتهاكات الواقعة على عقارات الدولة، التي توسعت دائرتها في الآونة الأخيرة بشكل أدى إلى هدر مساحات كبيرة من أراضي الدولة، كما تكمن أهمية البحث في الكشف عن أسباب التجاوزات والآثار المترتبة عليها.

فالبحث هذا محاولة لسـد فراغ في الدراسات القانونية العراقية التي تكاد تخلو من التعرض لهذا الموضيوع، وحتى لو تعرضت له فإنها تتناوله بشكل سطحي، وتكمن صعوبة هذه الدراسة في أنها تتصدى لظاهرة مستمرة، خطيرة ومعقدة، وبالتالي محدودة المصادر مقارنة بالمواضيع الأخرى.

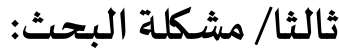

تكمن إشكالية البحث في أنّ الأحكام المنظمة للتجاوز على عقارات الدولة في العراق وفي إقليم كوردستان يعترها القصور والعديد من الثفرات، فضلا عن تفرقها بين مجموعة من القوانين والقرارات التشريعية، الأمر الذي يؤدي إلى تعدد الأحكام، وبروز العديد من الإشكاليات عند التطبيق، فعلى الرغم من توافر النصوص التشريعية في القانون العراقي إلاّ أنه لم تزل هذه الظاهرة تتفاقم يوما بعد يوم، وذلك لقصور التشريعات الحالية، وعدم مواكبتها للتغيرات السكانية والديموغرافية، فضلا عن عدم تطبيق القانون لمنع التجاوز ومعاقبة المتجاوزين، إذ هناك قواعد قانونية وقرارات في هذا الشأن، ولكن دون أنْ تترجم هذه القرارات بصورة عملية على أرض الواقع، مما يؤدي إلى التوسع في التجاوزات، وبعض من القوانين والقرارات وسيلة لإهدار الأموال العامة، وبعبارة أخرى أصبحنا بصددد تقنين الفسـاد. ويعد ملف التجاوزات من أكثر الملفات الشائكة، التي تخلق تحديا كبيرا لهيبة الدولة وسيطرتها على أملاكها التي يتم التجاوز عليها دون أنْ تتحرك؛ بسبب ضعف الإرادة من قبل السلطات، وعدم العمل جدياً في هذا المضيمار.

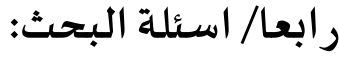

$$
\begin{aligned}
& \text { إنّ هذا البحث يعرض العديد من التساؤلات، كالآتي: } \\
& \text { / / ما هي التجاوزات، وما هي عناصرها؟؟ } \\
& \text { r/ ما هي الأسباب والعوامل التي تؤدي الى التجاوزات؟. }
\end{aligned}
$$




\section{خامسا/ أسباب اختيار موضيوع البحث: تمثلت أسباب اختيار موضوع البحث فيما يأتي:} ا / ندرة الدراسات القانونية في هذا المجال في العراق وإقليم كوردستان، التي تبحث في جدوى العمل بالقوانين الحالية التي تعالج ظاهرة التجاوزات على عقارات الدولة.

r / التوسع في التجاوزات على عقارات الدولة، إذ تحولت التجاوزات إلى ظاهرة خطيرة ومستمرة، حتى وصلت إلى أعداد مخيفة، وشمل التجاوز العقارات المخصصة للمنفعة العامة كالطرق والأرصفة والحدائق العامة، وكذلك العقارات المخصصة للمنفعة الخاصة كالأراضي الزراعية والسكنية.

$$
\text { سهادسـا/ أهداف البحث: }
$$

ا / إظهار مفهوم التجاوزات، والكشف عن التجاوزات من حيث النوع والكم وتد اعيتها التي تفاقمت، والوقوف على حجم تلك التجاوزات بصورها المختلفة، ودراسة التجاوزات من حيث أشكالها وأسبابها وآثارها الخطيرة والسلبية على كل الجوانب. r / معرفة حجم المشكلة التي تعاني منها المدن العراقية عن طريق التجاوز، ومدى تأثيره من كل الجوانب، سواء التأثيرات القانونية أو التأثيرات البيئية والخدمية أو التأثيرات الاقتصادية.

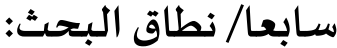

يتحدد نطاق هذه الدراسة بدراسة القواعد القانونية الواردة في التشريع العراقي التي تناولت بالتنظيم منع التجاوزات على عقارات الدولة وإزالتها، وبيان كيفية معالجة المشرع العراقي لهذه الظاهرة.

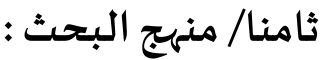

يعتمد الباحث في دراسته على المنهج التحليلي الذي يركز على عرض المشكلة ودراستها، والذي يقوم على أساس استقراء وتحليل النصوص القانونية والأحكام المنظمة للتجاوز على عقارات الدولة والحماية القانونية لها.

\section{تاسعا/ خطة البحث : ت}

استنادا إلى ما تقدم فإننا نقسم البحث إلى مبحثين، حيث نتناول في المبحث الأول ماهية التجاوز على عقارات الدولة وذلك من خلال ثلاثة مطالب، ففي المطلب الأول نتطرق إلى تعريف التجاوز على عقارات الدولة، ومن ثم في المطلب الثاني نبين أركان التجاوز على عقارات الدولة، أما المطلب الثالث فخصصناه للبحث عن خطورة التجاوز على عقارات الدولة، كما في المبحث الثاني نتناول أسباب التجاوز على عقارات الدولة، وذلك من خلال ثلاثة مطالب، ففي المطلب الأول نتطرق الى الأسباب السياسية، أمّا المطلب الثاني فنخصصيه للأسباب القانونية، وفي المطلب الثالث ندرس الأسباب الاقتصادية والاجتماعية، كما ختمنا البحث بذكر ما توصلنا إليه من الاستنتاجات و التوصيات. 


\section{ماهية التجاوزعلى عقارات الدولة}

يعمل القانون على تنظيم سلوك الأفراد داخل المجتمع بوسائل عدّة، وذلك بهدف تسيير الحياة بصورة طبيعية منتظمة، تكون فيها الحقوق مصانة، بحيث يكون الشخص بمنأى عن التجاوز لحقه والاعتداء عليه. وانطلاقا من الحقيقة أعلاه تتمتع الملكية بحماية أوجد لها المشرع قواعد عدة، منها دستورية ومنها تشريعية، فإذا كانت الدولة حريصة بذاتها على صيانة الحقوق للمواطنين فمن باب أولى أنْ تعمل وتحرص على حقوقها وعلى وجاه التحديد ممتلكاتها التي تمثل العقارات عنصرا مهما منها، فعلى الرغم من أنّ غاية القانون هي تنظيم شتى مجالات حياة الأشخاص، إلا أنّ الخروج عن قواعده أمر متوقع لا يمكن إنكاره، إذ

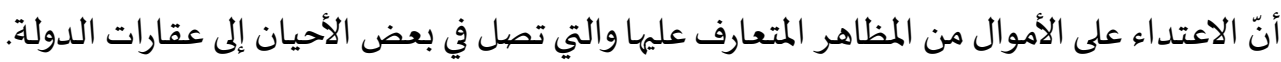
تعد التجاوزات على عقارات الدولة من أخطر المشكلات التي تواجه الدولة، وذلك لعلاقتها بالنظام العام، فضلا عن مسـاسها بحقوق المواطنين إذ يغتصب المتجاوز حقوق غيره، فضلا عن ضررها البالخ على الدخل القومي للبلد، فهي تشكل في معظمها خسارة عند حصولها وفي معالجتها، وهذه المثكلة تعاني منها الحكومات باستمرار، على الرغم من صدور كثير من القوانين والقرارات من أجل معالجتها والحيلولة دون وقوعها. نقسم هذا المبحث إلى ثلاثة مطالب نتناول في المطلب الأول مفهوم التجاوز على عقارات الدولة، وفي المطلب الثاني ندرس أركان التجاوز على عقارات الدولة، ونخصص المطلب الثالث لمخاطر التجاوز على عقارات الدولة.

\section{المطلب الأول}

\section{تعريف التجاوزعلى عقارات الدولة}

التجاوز لغةة: مأخوذ من الفعل الماضي (تجاوز)، (تجاوزَ على/تجاوزَ عن / تجاوزَ في)، فيقال تجاوز يتجاوز تجاوزا، فهو متجاوِز والفعول مُتجاوَز، وبهذا المعنى فهو أقرب إلى الخروج والاعتداء، وعدم الالتزام، وتأتي كلمة التجاوز بمعانٍ عدة منها (المخالفة والخروج عن اللائق،

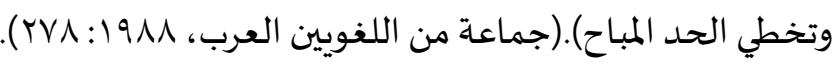

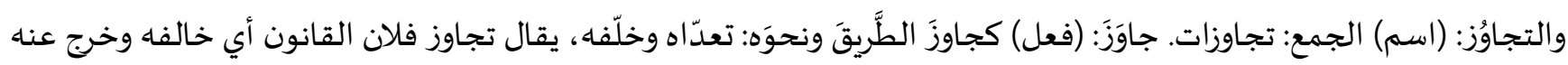

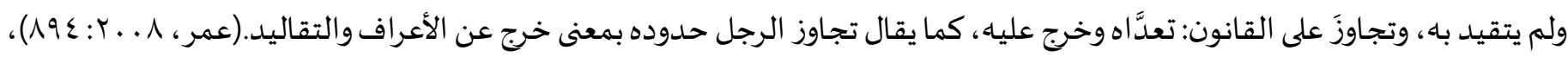

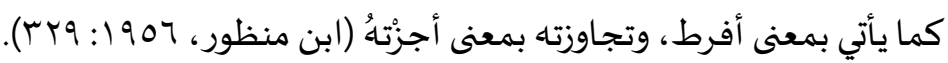
وتجاوز المكان جازه وتخطاه وتجاوز في الشيء أفرط فيه، والتجاوز تخطي الحدود المسموحة بها أي تجاوز السلطة (معلوف، 997 ا:

أمّا اصطلاحا فيقصد به عدم الالتزام بما هو مألوف وسائد بين الناس، أي الخروج عن إرادة المجتمع وشق عصا الطاعة والتمرد على القيم والعرف الاجتماعي وانتهاك القانون، وعدم الخضوع لإرادة المجتمع، فالتجاوز عمل محرم شرعا؛ لأنه اعتداء على مال الغير سواء كان ذلك الغير أفرادا أم حكوماة، ويدخل التجاوز على الأرض ضمن نطاق التحريم الشرعي، إذ التجاوز في الشريعة الإسلامية هو غصب الأرض، وقد نص الحديث الشريف على ذلك بوضوح، إذ قال رسول الله (صلى الله عليه وسلم)(من ظلم قيد شبر من الأرض طوقه الله بسبع أرضين)(صحيح البخاري: 190ب؛ صحيح مسلم: • (171)، ويعدّ الأرض من أموال الدولة، فإنّ التجاوز عليها يعد حراما؛ لأنه يدخل ضمن مفهوم الغصب، ويشمل ذلك استعمالات الأرض كلها، فمن خلال هذا المبدأ تم منع تجاوز الاستعمال على الآخر، إذ تم تحديد استعمالات 
الأرض كل واحد على حده في المدن الإسلامية باعتماد مبدأ العقاب والثواب، أي يكافأ المرء على الأعمال الحسنة ويحاسب على الأعمال السيئة(Younan) (985 : 1985).

والتجاوز هو مجمل ما يقوم باه الأفراد والجماعات والهيئات الرسمية وغير الرسمية من إتلاف وتشويه متعمد وغير متعمد لبنية المدن، وهي الأماكن الحضارية، مما يؤدي إلى تغيير صورتها التي ينبغي أنْ تكون عليها المدينة وتظهر بها.(منسى، V . . Y. 7 ). أمّا على الصعيد التشريعي، فلم يعرف المشرّع العراقي ولا التشريعات العربية المقارنة مصطلح التجاوز، إنما وردت في النصوص التصري التشريعية صور للتجاوزات وأحكام معالجتها، كما ينص القرار رقم عه ا لسنة ا . . ب الصادر عن مجلس قيادة الثورة (المنحل) على أنه (يعد تجاوزا التصرفات الآتية الواقعة على العقارات العائدة للدولة والبلديات ضمن حدود التصاميم الأساسية للمدن دون الحصول على موافقة أصولية:-

1 / البناء سواء أكان موافقا أم مخالفا للتصاميم الأساسية للمدن.

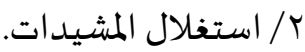

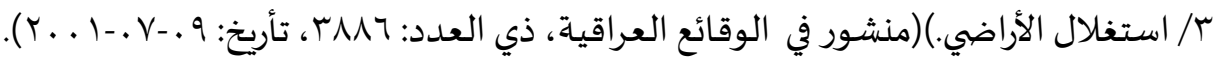
وقد جاء في قرار محكمة التمييز بصدد النظر في الطعن المقدم أمامها (أنّ المدعي عليه قد تجاوز بدون حق أو مسوغ قانوني على

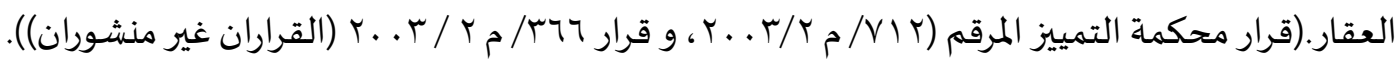
أمّا المشرع الكوردستاني فقد عرّف بدوره التجاوز على عقارات الدولة في المادة (ع/ أولا) من قانون منع وإزالة التجاوز على أراضي الدولة

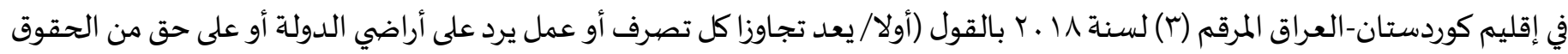
الواردة على هذه الأراضي إذا وقع دون ترخيص قانوني، أو بالمخالفة لأحكام القوانين النافذةومنها مائتي: / / غصب واستعمال ووضع اليد على أبنية الدولة. ب / تشييد المنازل والأبنية بمختلف أنواعها، ولأي غرض كان سواء أكان موافقا للتصاميم الأساسية أم لم يكن، وكذلك يشمل الأراضي التي تقع خارج حدود البلديات. Г/غصب الأرض أو غصب جزء منها. ع/ تغيير جنس الأرض، واستعمال الأرض، وتغيير استعمالات الأرض. 0/ حفر الأرض، أخذ التربة (التربة الاعتيادية أو المختلطة)، تغيير مجرى المياه السطحية، وتغيير مسار المرور. 7/ تعطيل أو تغيير حق

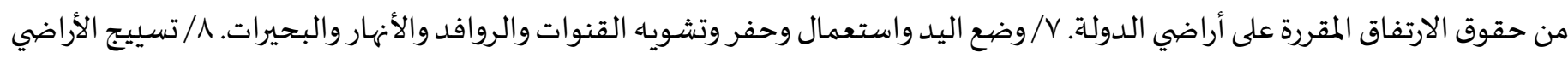
والأراضي الصخرية والمراعي والغابات والزراعات خلافا للقوانين النافذة. 9/ بيع وهبة وإيجار الأراضي لأغراض الزراعة وإقامة البساتين

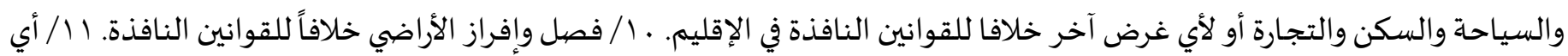
تصرف آخر، عدا ما هو مذكور في الفقرات السـابقة، يقع على أراضي الدولة دون الحصول على الموافقات الأصولية. ثانيا/ استعمال جميع أو جزء من شارع، رصيف، ساحة، حديقة، متنزه أو أي مكان عام بصورة مؤقتة أو دائمة للمصلحة الخاصة خلافاً للقوانين النافذة في الإقليم.).

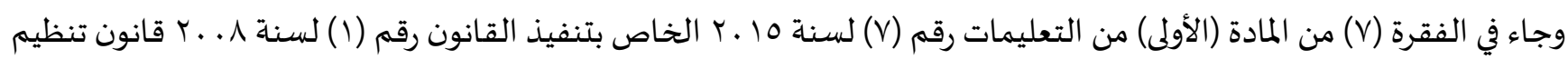
الحقوق التصرفية في الأراضي الزراعية لإقليم كوردستان-العراق بأن (التجاوز في الأرض الزراعية هو التصرف في الأرض دون سند من قرارات

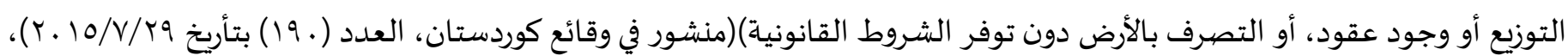
وهذا التعريف يخص التجاوز على الأراضي الزراعية دون الأراضي الأخرى. وعلى الصعيد الفقهي هناك من يعرف التجاوز بأنه (التغير في صنف استعمالات الأرض عن طريق استيلاء المواطنين على الأراضي

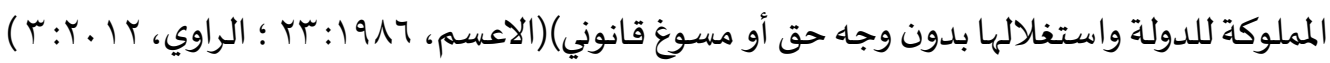


كما عرف بأنّه (كل ما يحصل من تغير في استعمالات الأرض المخطط لها، أو كل ما يقوم باه الأفراد من أنشطة وفعاليات مخالفة للقانون، أو غير شرعية داخل المدينة و خارجها)، وعرف ايضا بأنه (تعدي أو انتهاك حرمة ملك الغير بدون وجه حق وانعدام المسوغ القانوني

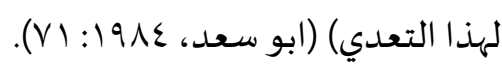

وبدورنا نفضل أنْ يعرف التجاوز بأنه (كل تعدٍِ متعمد على عقار عائد للدولة دون أنْ يسبقه مسوغ قانوني).

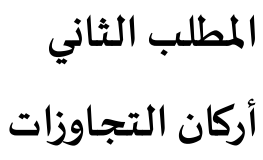

عن طريق استقراء التعاريف والنصوص القانونية المتعلقة بالتجاوز السالف ذكرها يستشف أنّ للتجاوز ثلاثة أركان، المتجاوز، عدم وجود مسوغ قانوني و ملكية العقار للدولة:

\section{الركن الأول/ المتجاوزون}

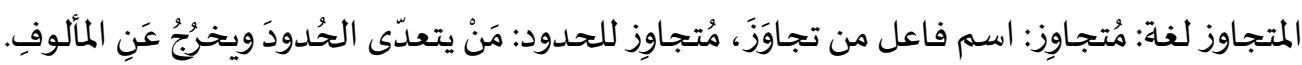
وعرف قانون منع وإزالة التجاوز على أراضي الدولة في إقليم كوردستان-العراق رقم (ץ) لسنة مل ــ (المتجاوز) في المادة (ا ، الفقرة 9)، إذ تنص على أنّ (المتجاوز الشخص والجهات التي تقوم بتصرف وارد في المادة (ع) من هذا القانون دون الحصول على ترخيص قانوني وخلافا للقوانين النافذة).

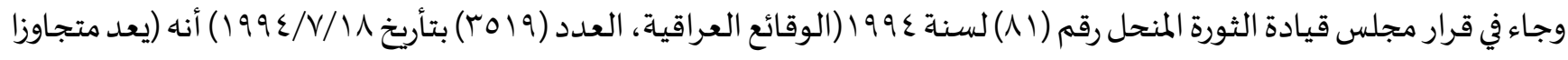

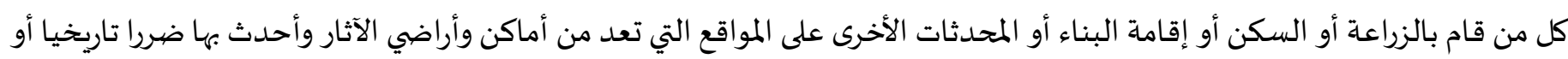
ماديا). فهو الشخص أو الجهة التي تقوم بأي تصرف أو عمل يرد على عقارات الدولة أو على حق من الحقوق الواردة على هذه العقارات، دون الحصول على ترخيص قانوني أو بالمخالفة لإحكام القوانين، سواء كان شخصا طبيعيا ام شخصا معنويا، وسواء كانت التجاوزات عن طريق شخص واحد ام عن طريق مجموعات خارجة عن القانون. والجدير بالذكر أنّ مؤسسات الدولة قد تقوم بالتجاوز على عقاراتها، وذلك عند الاستيلاء أو إحداث التغيرات على العقارات التابعة لمؤسسات أخرى تابعة للدولة، وتتحقق التجاوزات أيضا من قبلها إذا تصرفت بالعقارات على وفق اعتبارات لا تتلائم مع التشريعات والتعليمات المرعية. ومن الجدير بالذكر أنّ قضية التجاوز على ممتلكات الدولة خرجت من نطاق حالات معينة، فهي في الوقت الحاضر أصبحت ظاهرة تضفى عليها صببغة قانونية بسبب عجز الحكومة عن مواجهتها، فالتجاوز لم يعد كما كان في السابق يمارس من قبل أفراد عاديين، إذ أنّ مانّ الفاعلين الرئيسيين له الآن هم الذين يمثلون السلطة داخل الدولة، فضلا عن الأحزاب والتنظيمات السياسية المتنفذة داخل الوطن. من خلال ما تقدم يتضح أنّ المتجاوز على عقارات الدولة يتمثل في إحدى من الأنواع الآتية:أولا: الأحزاب والمنظمات السياسية بصرف النظر عما إذا كانت مشاركة في الحكومة أم لا، فهي تشارك في التجاوز. ثانيا: الأشخاص 
والمقصود بهه أولئك الذين ينتمون إلى الأحزاب المتنفذة داخل الدولة سواء كانوا أفرادا أم أشخاصا اعتبارين، إذ هناك حالات متنوعة من التجاوز تمارس من قبلهم، تتمثل في الاستيلاء على بنايات أو دور أو قطع أراض من قبل بعضهم، وصولا إلى حالات التجاوز على الأرصفة والشوارع التي يقوم بها في الغالب باعة الرصيف وأصحاب المحال التجارية، والتي تجعل السير في هذه الشوارع غاية في الصعوبة. ثالثا: الحكومة يؤخذ على الحكومة إقدامها على التجاوز والتصرف بعقارات الدولة خارج الإطار القانوني بهدف كسب ولاء الأفراد لها، وعجزها عن

$$
\text { يستشف مما تقدم أنّ العقارات المتجاوز عليها تنقسم إلى ثلاثة أنواع رئيسة هي: }
$$
مواجهة التجاوز. r/ البنايات الحكومية التابعة لمؤسسات الدولة والتي تم شغلها والاستيلاء عليها من قبل بعض الأحزاب السياسية والشخصيات المتنفذة مثل البنايات المخصصة للدور السكنية والقصور كذلك دور الضيافة وغيرها. r/ المساحات الفارغة والأراضي الزراعية التي استولى علهها وشغلها المواطنون وبنوا عليها البيوت السكنية لتتحول بذلك إلى نوع من العشوائيات السكنية.

\section{الركن الثاني/ عدم وجود مسوغ قانوني}

إنّ المقصود بهذا الركن هو أنْ يفتقر المتجاوز إلى سند قانوني يضفي على تعديه على عقارات الدولة صفة المشروعية، ويتحقق ذلك عندما لا يستند إلى حق عيني أو شخصي على عقار عائد للدولة، كالملكية والمساطحة وحق التصرف أو الإيجار أو الترخيص بالتمليك أو بدونه، ويستوي الأمر حتى وإنْ كان هناك مسوغ قانوني سلفا، إلاّ أنّه ألغي لأي سبب كان أو سحب واستمر الشخص في ممارسة الأفعال التي تعكس التجاوز بمختلف أنماطها، سواء كان بالبناء أو الغرس أو وضع اليد أو السكنى وغيرها من التصرفات، والأمر نفسه بالنسبة للحالات التي تستند إلى مبرر قانوني عند انتهاء مدّهها، فاستمرار المساطح في استغلال محل المساطحة على الرغم من انتهاء مدة المساطحة يجعله متجاوزا، وإبقاء المزارع للأرض الزراعية التي استأجرها من الحكومة بعد انتهاء فترة الإيجار يعد من قبيل التجاوز، وكذلك استمرار موظف الدولة في شغل العين المأجورة بعد انتهاء خدمته بسبب إحالته إلى التقاعد أو عزله من الوظيفة أو نقله إلى مدينة أخرى أو بقاء ورثته في المأجور بعد مضي المدة المسموحة لهم يشكل تجاوزا على عقارات الدولة، على اعتبار أنّ كل حالة من الحالات التي أشرنا إلهها قد انتهى مسوغها القانوني، فلم يعد هناك مبرر للاستمرار في حيازة العقارات تلك. كما أنّ التعدي بوضع اليد لا يشترط أنْ يكون كليا حتى نكون بصدد التجاوز، إذ هناك حالات يمثل التصرف فهها تجاوزا على الرغم من وجود مسوغ قانوني، إلاّ أنّه يكون قاصرا على أمر معين، وعلى الرغم من ذلك يقوم الشخص بالتجاوز مستخلا بذلك المسسوغ القانوني، كحالات تمليك الأراضي للأشخاص من قبل الدولة، إذ يستغل المستفيد هذا التمليك ويتجاوز باه على ما للدولة من الأراضي المتلاصقة بأرضها. وعلى الرغم من عدم وجود مسوغ قانوني عند المتصرف في عقارات الدولة مما يجعل منه متجاوزا إلا أنّ ذلك لا يعني الأخذ باه بصيورة مطلقة، ومفاد ذلك هو أنّه على الرغم من عدم وجود مسوغ قانوني فهناك حالات لا تشكل التجاوز بالمعنى الفعلي، وإنْ كانت تعكسها من الناحية القانونية، بحيث لا يترتب عليها مؤاخذة الفاعل وعده متجاوزا بشرط ألا يكون له يد فيها، كالغلط الذي يحدث عند تثبيت حدود الأراضي بخطأ من المهندسين والمساحين الرسميّين العاملين لدى البلديات والسجل العقاري، فإذا ما شـاب عملية إجراء تثبيت الحدود التي تسبق انتقال ملكية الأراضي بالبيع أو الفرز أو التمليك أو الافراغ غلط أو سهو، يكون المتصرف لله بمنأى عن المسؤولية، ولا تضفى عليه صفة المتجاوز على الرغم من افتقاره للمسوغ القانوني. 
تمثل عقارات الدولة العامة (الدومين العام)، وهو العقارات التي تملكها الدولة أو الأشخاص المعنوية العامة الأخرى، ملكية عامة وهي تخضع للقانون العام، وتخصص للنفع العام، كالطرق وشواطئ البحر والأهار والموانئ والحدائق العامة، والأصل أنْ لا تفرض الدولة رسما أو مقابلا للانتفاع به واستعماله، إلا في حالات خاصة بهدف تنظيم هذا الانتفاع، وبذلك تظل القاعدة العامة هي مجانية الانتفاع

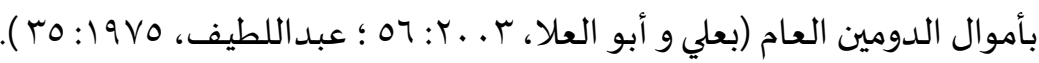
فالعقارات العامة هي ما تملكه الدولة من أموال مخصصة للنفع العام مثل الطرق والجسور والمستشفيات والدوائر الحكومية

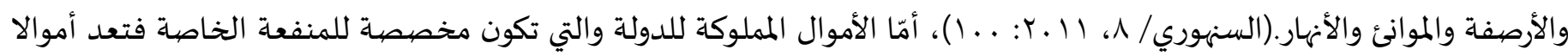
خاصة كالأراضي الزراعية المملوكة للدولة.

إنّ المعيار المعتمد من قبل المشرع العراقي للتمييز بين عقارات الدولة العامة والخاصة هو التخصيص، فإذا كان العقار مخصصيا للمنفعة العامة يكون من عقارات الدولة العامة (الدومين العام)، ويستوي في ذلك أنْ يكون التخصيص فعليا، كالطرق والجسور ...إلخ، أو

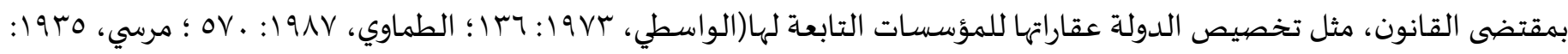

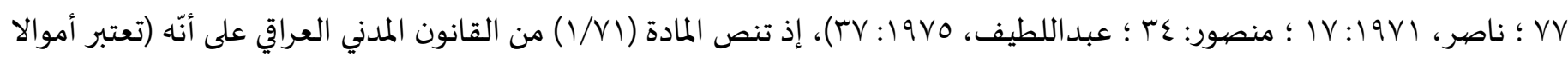
عامة العقارات والمنقولات التي للدولة أو للاشخاص المعنوية والتي تكون مخصصة لمنفعة عامة بالفعل أو بمقتضى القانون.). والأصل كما سبق الذكر أنّ الدولة هي التي تقوم بتخصيص العقارات لأغراض النفع العام، إلا إنّه بأمكان الأفراد القيام بالأمر نفسـه،

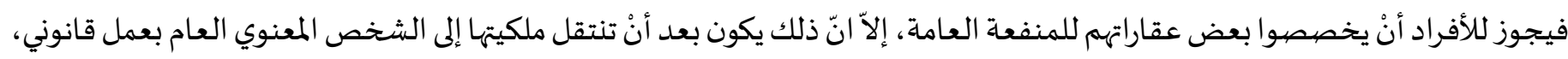
كالشراء أو الوقف أو الهبة أو الاستملاك، أو بعمل مادي كالالتصاق أو الحيازة، إذ لا يجوز أنْ تنتزع ملكية إنسان بالغصب أو الإكراه، وقد

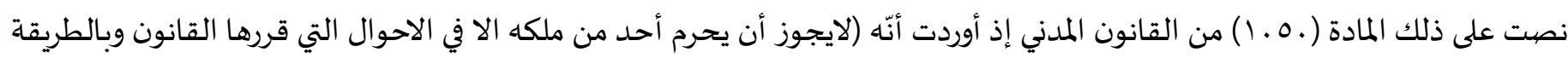
التي يرسمها، ويكون ذلك مقابل تعويض عادل يدفع اليه مقدما). وتكون العقارات مخصصة للاستعمال المباشر للجمهور إذا كان الأفراد ينتفعون بها مباشرة، والانتفاع المباشر من العقارات العامة من قبل الأفراد على نوعين، النوع الأول: انتفاع مشترك "جماعي" من قبل عامة الأفراد، ومثال ذلك: الطرق العامة والأنهار وشواطئ البحر ... الخيحا: 17 الخيحابعدها).

واستعمال العقار العام على هذا النحو يعد من مظاهر ممارسة الأفراد لحرياتهم الفردياة، كحرية المرور في الطرق العامة، وحرية التجارة عن طريق نقل البضائع بوساطة الطرق البرية والهرية، أو حرية القيام بالشعائر الدينية بإرتياد دور العبادة ... الخ. أما النوع الآخر من الانتفاع بالعقارات العامة فهو وإنْ كان يتم بشكل مباشر ولكنه لايتم بأسلوب مشترك وإنما بأسلوب الإشغال الخاص من قبل بعض الأفراد، ومثال ذلك الأملاك العامة المخصصة لاستعمالها كالأسواق، فيختص كل بائع بجزء منها لعرض بضائعه عليه، وكالمقابر العامة التي لا يمكن أن تستعمل إلا على نحو الاختصاص بجزء منها، وكالساحات العامة المخصصية لوقوف السيارات. أما العقارات المخصصة للمرافق العامة فتمثل الأموال المخصصة لتسيير وإدارة المرافق العامة جميعها، بصرف النظر عن أهميتها،

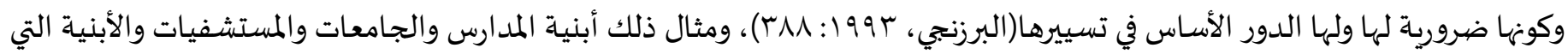

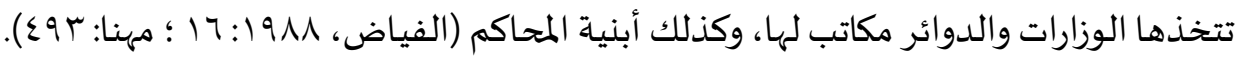
وبناء على ذلك لايعد من العقارات العامة العقارات المملوكة للأفراد أو للأشخاص المهنيين، وكذلك العقارات المملوكة للدولة ملكية

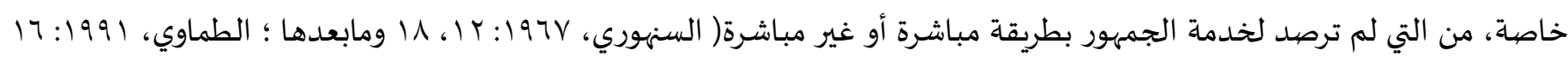
ومابعدها). 
ويترتب على ذلك أنّ العقار غير المخصص للمنفعة العامة وإنْ كان يعود للدولة ملكيته فإنه لاتسري عليه الأحكام والقواعد المتعلقة بالعقار العام(ومن هذه القواعد إنّ العقارات العامة لايجوز التصرف فهها أو الحجز عليها أو تملكها بالتقادم (م/VY فـ من القانون المدني العراقي)، كما لايجوز التمسك بالالتصاق لاكتساب ملكية العقار العام.(ناصر: إب؛ طماوي: ه970)، ويطلق على هذا العقار اسم (الدومين الخاص) وهو الذي تملكه الدولة ملكية عادية، كملكية الأفراد لأموالهم، ويمكن التصرف به بالبيع أو نحوه، ويخضع لأحكام القانون الخاص(يلحظ هنا أنّ الشارع أحيانا يحمي الملكية الخاصة للدولة أكثر من حمايته لملكية الأفراد، فالمدة اللازمة لكسب ملكية الأراضي الأميرية أو الموقوفة (جس سنة) (م/9 إ ا من القانون المدني العراقي) في حين إنّ المدة اللازمة لكسب ملكية الأفراد بالتقادم الطويل هي (10 سنة) (م/10/ إمن القانون المدني العراقي). وعلى هذا يجب اعتبار العقار عاماً بتوفر شروط وهي (أن تكون تلك العقارات مملوكة للدولة، وأن يتم التخصيص للمنفعة العامة بالفعل أو بموجب نص في القانون كالطرق العامة والحدائق). وإنّ لاستعمال العقار العام قواعد يجب أنْ تراعى من قبل مستعمليه، منها: ضرورة مسايرة طرائق الاستعمال للأهداف السياسية التي خصص العقار العام من أجل تحقيقها، ويجب أنْ لا يؤدي الاستعمال إلى تعريض عناصر العقار العام إلى خطر الهلاك، وقد يتم تخصيص العقار العام للانتفاع المباشر لأبناء المجتمع، كاستعمال الجمهور للشوارع دون الحصول على ترخيص من الإدارة، كما يجب أنْ تتوفر المساواة

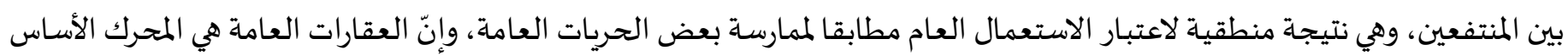
لاقتصاد أي بلد، وعليه لا بدّ من توفير الحماية اللازمة لهذه العقارات. مما سبق يمكن القول أنّ العقارات العامة هي عقارات مخصصة للمنفعة العامة، وتخصيصها لهذا الغرض يقتضي إفرادها بأحكام خاصة تكفل حمايتها من كل اعتداء قانوني أو مادي يمكن أنْ يعطل تحقيق الغرض منها، ويضفي المشرع في مختلف دول العالم حماية خاصة للعقارات العامة نظرا لكونها تعم نفع المجتمع كله، ويتوقف على حمايتها وصيانتها استمرار عمل المرافق العامة بشكل منتظم لخدمة جمهور المواطنين، وتتعدد صهور الحماية فمنها ماورد في القانون المدني، ومنها ما تضمنه قانون العقوبات ومنها ماورد في صلب الدستور، وهذا ما ضمّنّه المشرع العراقي، إذ جعل الحماية واجبة على الدولة وأفراد الشعب. أمّاعقارات الدولة الخاصة (الدومين الخاص) فهي العقارات المملوكة للدولة أو الأشخاص المعنوية العامة أو الولاية أو البلدية، ملكية خاصة ولا تخصص للنفع العام، وللدولة أو الأشخاص المعنوية العامة الحق في استغلالها أو التصرف فهها، كتصرف الأفراد في أموالهم

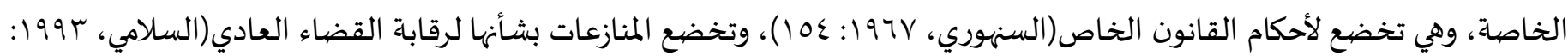

ومن هذه العقارات مثلا، الأراضي الأميرية الصرفة التي تملكها الدولة، وتشرف عليها مديرية الأملاك والأراضي الأميرية العامة، أو

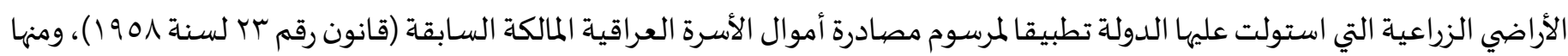
كذلك العقارات التي تؤول إلى الدولة بعد وفاة أصحابها بلا وارث، وكذلك أراضي الموات.(عبداللطيف: . ع). وتتمثل أهمية هذه العقارات بأنها تنمي موارد الدولة، فتعمل على تزويدها بما تنتجه من عوائد و غلات وثمار، ويكون لها الحق في استخلالها ماليا بالطرائق المقررة قانونا، سواء عن طريق الاستغلال المباشر لها أو عن طريق تأجيرها (أبو زيد، 19 19 . ـ 1). 


\section{المطلب الثالث \\ مخاطر التجاوزعلى عقارات الدولة}

يؤدي التجاوز إبتداءً إلى الاعتداء على النظام العام، باعتباره ماسـا أهم الأسس والركائز الجوهرية التي يقوم عليها المجتمع وهي القانون، وعند تلكؤ الدولة في مواجهة التجاوزات من خلال عدم محاسبة المتجاوزين، وعدم إيجاد الحلول الناجحة للقضاء على أسباب التجاوز، يتحول التجاوز من حالات معدودة استثنائية ينكرها المجتمع إلى ظاهرة واسعة يقوم بها معظم أفراد المجتمع لو سنحت لهم الفرصية، مما يؤدي إلى تشويش مفهوم النظام العام الاجتماعي والاقتصادي والأخلاقي وتغيره نحو الأسوأ، وإجمالا تتمثل مخاطر التجاوز على عقارات الدولة فيما يأتي:

\section{أولا/ إهدار المال العام}

كما هو معلوم بأنّ العقار هو وسيلة الدولة في مجال التعمير والتخطيط العمراني، وهو آلية أساسية لضمان حق المواطنين في السكن، وبالتالي فالعقار يساهم بدور فعال في تنفيذ السياسات العمومية الرامية إلى تحسين ظروف عيش المواطنين ومحاربة الفقر، كما يسهم في الحركة التنموية، وذلك في ضوء التحولات الاقتصادية والديمغرافية المتسارعة التي يشهدها العصر الحالي، فهو يلعب دورا مهما في تنمية الاستثمار في القطاعات الحيوية كلها في البلاد، كالقطاع الصناعي والقطاع السياحي والزراعي، فضلا عن ذلك، فالعقار يعد آلية لتطوير وتنمية في مختلف المرافق الحياة. إنّ التجاوز على عقارات الدولة يلحق أضرارا بميزانية الدولة، وإنّ استغلال الدولة لعقاراتها بصورة سليمة يعود عليها بإيرادات مادية كبيرة، إذ تساعدوتساهم في تطوير اقتصاد البلاد، إذ إنّ الإيرادات المتحصلة من عقارات الدولة تكون داعمة للموازنة العامة بنسبة ملحوظة،

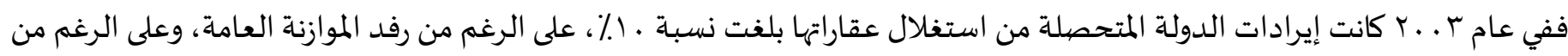
أنّ هذه الإيرادات تحصلت عن طريق الأجور الرمزية لعقارات الدولة التي استغلت في تلك الفترة. فعندما يتم وضع يد على هذا النمط من العقارات المملوكة للدولة يترتب عليه حرمان الدولة من غلتها، مما يؤدي إلى فقدها لأحد أهم

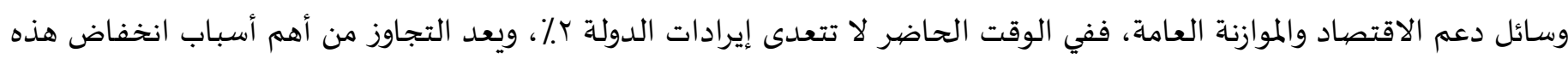
الإيرادات، فالتجاوز يحصل نتيجة إحداث فجوة في الموازنة، والتقليل من تعدد مصادر إيرادات الدولة وتنوعها، فكما هو معلوم كلما كان

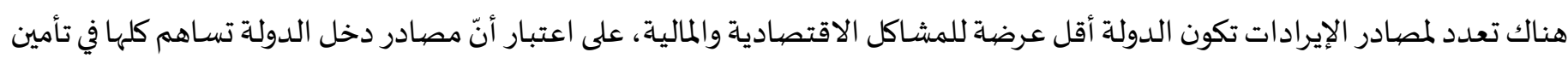

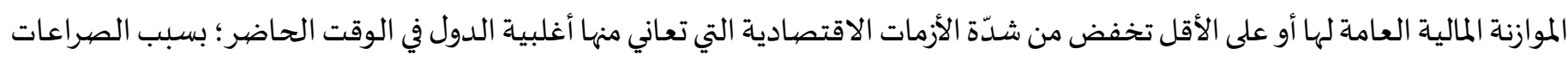
السياسية والأزمات وانتشار الأمراض والاوبئة منها فايروس كورونا.

\section{ثانيا/ إضعاف سيادة الدولة}

من مخاطر التجاوز على عقارات الدولة أيضا ظهور الدولة ومؤسساتها بصورة ضعيفة بحيث يفقدها الاحترام والهيبة، واللتان تعدان من أهم مظاهر قوتها، إذ يكون من الطبيعي أنْ تظهر الدولة بصورة لا تليق بسيادتها عندما تصبح أهم ممتلكاتها عرضة للاستيلاء من دون أنْ تتمكن من محاسبة المسؤولين عن ذلك التجاوز.

إنّ لعقارات الدولة صلة وثيقة بأمنها وسيادتها كونها تمثل ثروة، إذ كانت ولا تزال لها من الأهمية القصوى من الجانبين السياسي

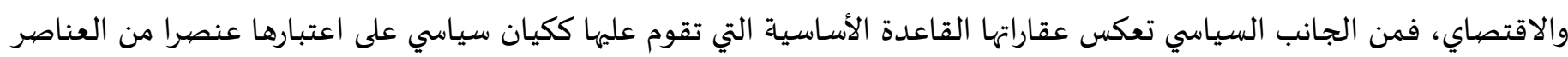

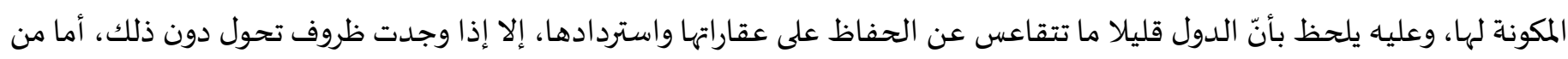


الجانب الاقتصادي فيلحظ بأنّ عقارات الدولة وبمختلف أنماطها تشكل مصدرا رئيسا لمدخلاتها المالية، فهي مستودع العطاء والتنمية، ومستقر الإنسان ومعيشته.

\section{ثالثا/ اللامساواة}

يعد التجاوز خروجا عن مبدأ العدل والمساواة، فمثلا تمليك الأراضي المتجاوز عليها لشخص أو لأشخاص معينين يمثل تفضيل قلّة من الأشخاص على عامة الناس، أي تفضيل المتجاوز على الأشخاص الذين يحرصون على حفظ عقارات الدولة والالتزام بالقانون. إنّ عدم محاسبة الدولة للمتجاوزين على عقاراتها لا يقتصر على إضعاف سلطة الدولة فقط، وإنما يضيف إليه معضلة اجتماعية تتمثل في تفضيل المواطنين بعضهم على بعض، وإنْ كانت بصورة غير مباشرة، فالتجاوز على عقارات الدولة يؤدي الى نتائج سلبية تقلل من هيبة الدولة وسلطتها. ففي الدول التي يتفشى فيها الفساد والمحسوبية تبرز فئة قليلة تتسم بالاستغلالية، وظيفتها الاستفادة من موارد الدولة بطرائق غير مشروعة، وهذا ما يلحظ بجلاء في العراق في الوقت الراهن، ومن أبرز الأعمال غير المشروعة التي تقوم بها الاستيلاء والتجاوز على عقارات الدولة، ويترتب على ذلك حصولها على عقارات دون مقابل أو مقابل شيء تافه، وفي المقابل تفتقر أغلبية الأشخاص إلى فرصة كسب أو

الحصول على عقارات حسب احتياجاتهم، مما يؤدي إلى التمييز بين الأشخاص والمواطنين وتفضيل القلة على الأغلبية من دون وجه حق. بعد سقوط بغداد سنة r . . r ، أصبحت عقارات الدولة غير محمية وتم التعامل معها وإلى الوقت الحاضر كغنيمة تتصرف بها السلطة خارج إطار القانون والمساواة، فأصبحت كامتياز تمنح للمؤيدين للسلطة بوسائل مختلفة، منها التجاوز وعدم محاسبة المتجاوزين، وأكثر من ذلك يؤخذ على السلطة تمليك عقارات المتجاوز علهها على المتجاوزين، بخلاف ما يقضي باه العدل من ضرورة محاسبة المتجاوزين من جهة، وتحقيق المساواة بين أفراد المجتمع. إنّ تحقيق المساواة في مسألة تملك العقار من قبل الأشخاص لا تعني منح فرصة لكل فرد من الحصول عليه عن طريق التجاوز، فالقصد هنا هو وضع إطار قانوني متين، يمكن الأشخاص على وفق مبدأ المواطنة من الحصول على عقارات كل حسب حاجته، والنشاط الذي يمارساه، والخدمة التي يقدمها لوطنه. فالتجاوزات وعدم المحاسبة علهها تؤدي المى إضعاف الثقة بالدولة ومؤسساتها، مما يفقد القانون هيبته، ولاسيما أنّ المتجاوزين يملكون تعطيل القانون، وقتل القرارات في المهد، وتصبح مخالفة القانون هي الأصل، واحترام القانون هو الإستثناء.

\section{رابعا/ يؤدي الى كارثة بيئية}

التجاوزات تترك آثارا اقتصادية واجتماعية وبيئية وأمنية وتخطيطية متعددة، وهذه الآثار ليست مستقلّة عن بعضهها، بل إنّ أي خلل اقتصادي يخيم بظلاله على الجانب الاجتماعي والأمني والبيئي والتخطيطي، ويترتب على ذلك أنّ المدن تكون معتلة جراء عدم الالتزام بما خطط لها لما خلفته ظاهرة التجاوزات من الآثار. فمن الآثار السلبية للتجاوز على عقارات الدولة حدوث التلوث البيئي في المدن، إذ تطرح التجاوزات السكنية كثيرا من النفايات المنزلية، التي تعجز الجهات البلدية عن إزالتها بشكل يومي منتظم، فضلا عن التلوث البصري فيتجلى بأوضح صوره في استعمال متجاوزي التجمعات السكنية في بعض الأحياء مواد بناء وتشطيبات متنوعة وغير متجانساة، وتصاميم لا تتناغم مع المشيدات السكنية الموجودة فعلا، مما يعني مشهد مشوه حضريا، كما أنّ إزالة العديد من بساتين الفاكهة والمساحات الخضراء داخل المدن تترتب عليها التوسع في حالة التصحر، فضلا عن تدهور التربة وحرمان المدينة من حزاهها الأخضر الذي لله دور كبير في تنقية هواء المدينة. 
إنّ الأراضي الزراعية والبساتين بشكل عام ثروة وطنية يتوجب قانونيا على أصحابها وذوي العلاقة فهها والمسؤولين الاهتمام بها، على وفق منهجية الدولة والتعليمات والقرارات الصادرة من الجهات المختصة،، ورعايتها وتطويرها، والامتناع عن كل ما يؤدي إلى تلفها والإضرار بها إذ تعد ظاهرة التجاوز من المخاطر البيئية ذات الأثر المباشر في التدهور الواضح في مكونات النظام البيئي، وما تتركه هذه الظاهرة من تدهور التربة أولا وما تعانيه من تملح وتغدق يؤثر سلبا في فقرها وتعريتها، كما يؤدي إلى انعدام الغطاء النباتي، وبالتالي تصحر هذه الأراضي، وزحف الكثبان الرملية نحو المساحات المزروعاة، لذا لابد من الحد منها ومحاولة إيقافها والقضاء عليها؛ لأنّ استمرارها يؤدي إلى إلحاق الضرر بالبيئة.

\section{المبحث الثاني \\ أسباب التجاوزعلى عقارات الدولة}

تختلف وتتنوع أسباب التجاوزات في أي مدينة تبعا لجملة المتغيرات السياسية والاقتصادية والاجتماعية للمدة الزمنية التي حدثت بها التجاوزات، وفي ظل الأوضاع التي مر ويمر بها العراق، بات من الضروري استدراك ما حصل، وما قد يحصل للمدن العراقية في ظل أوضاع استثنائية، جعلت مدن العراق تعيش حالة من الإرباك على الأصعدة جميعها، إنّ ظاهرة التجاوزات لم تقتصر على زمان ومكان محدد، بل تختلف من حيث النوع والنسب داخل الدولة الواحدة من وقت لآخر، ومن منطقة الى أخرى، حسب الظروف الاقتصادية والاجتماعية والسياسية والأمنية سواء من حيث الأسباب والآثار أو أسلوب معالجتها، لذلك أصبح من الضروري رصد أسباب هذه التجاوزات ومن ثمّ البحث عن المعالجة.

ومع أننا لا نقر بمبدأ التجاوز على عقارات الدولة مهما كانت مبرراته، ولكن متطلبات استكمال البحث تقضي وجوب التحري عن العوامل التي أدت الى التجاوز على تلك العقارات، إذ توجد أسباب تدفع القائمين إلى ممارستها دون تردد، الأمر الذي يتطلب فهم هذه الأسباب ومعرفتها، وعليه نخصص هذا المبحث لدراسة أسباب التجاوز على عقارات الدولة وذلك من خلال ثلاثة مطالب، نبحث في المطلب الأول الأسباب السياسية للتجاوز على عقارات الدولة وفي المطلب الثاني نتناول الأسباب القانونية، أما المطلب الثالث فنخصصها لدراسة الأسباب الاقتصادية والاجتماعية للتجاوز على عقارات الدولة.

\section{المطلب الأول \\ الاسباب السياسية}

أظهرت المسوحات الأخيرة لوزارة التخطيط الاتحادي لعام ؟ ـ ـ أنّ نسبة المتجاوزين على عقارات الدولة بلغت (V,V\%) من مجموع

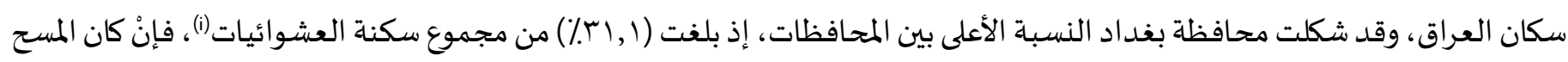
المشار إليه في عام r| ـ ب فما بالك بوضعها الحالي، وما ستؤول إليه مستقبلا. استمرت مسألة التجاوز على عقارات الدولة في العراق وصاحبت مختلف الحكومات والأنظمة التي استولت على الحكم، والذي يذكر في هذا السياق أنه كلما كان نظام الحكم في العراق يتسم بالقوة كانت التجاوزات تتجهه نحو الحصر والسيطرة علها، وإن لم تنتهي بشكل نهائي، إلا إنّا كانت تتراجع بشكل ملحوظ إلى حالات بعد أنْ كانت ظاهرة، إذ كانت ترصد حالات معينة من التجاوز في عموم العراق، لا تشكل خطورة على المصالح العامة بكل جوانها السياسية والجغرافية والاقتصادية والاجتماعية والامنية. 
بعد إنهاء حكم النظام البعثي في العراق سنة r . .r عاد التجاوز على عقارات الدولة بصورة ملحوظة وبنسب كبيرة تجاوزت مرحلة الظاهرة، إذ أصبح في الوقت الحاضر واقعا تعجز السلطة عن وضع حد له إلى درجة تغيره لكثير من التصاميم الرسمية المعدة للمدن في العراق.

وإنّ النخبة السياسية وعلى وجه التحديد النخبة الحاكمة والمتنفذة داخل الدولة والإقليم تؤخذ عليها مسؤولية الانتشار المكثفف للتجاوز على عقارات الدولة وذلك للأسباب التالية: / / إنّ بداية التجاوز على عقارات الدولة كانت بفعل هذه النخبة بكافة أنواعها، سواء من حيث الاستيلاء على الأراضي أو الأبنية أو منشآت الدولة. r/ تسهيل التجاوز لمن هم محسبوبون على النخبة الحاكمة، سواء في السماح لهم بالتجاوز على عقارات الدولة ابتداءً أو حمايتهم من المسألة القانونية بعد قيامهم بالتجاوز.

r/ التعامل مع عقارات الدولة للحفاظ على قاعدتهم، فأصبح التجاوز وسيلة لهذه الغاية. إنّ إدارة الدولة على وفق النمط الحالي تظهر أنّ السلطة المتمثلة بالأحزاب السياسية في الدولة الاتحادية وإقليم كوردستان العراق تسبب في زيادة التجاوز على عقارات الدولة، وانتشاره بطريقة مباشرة وغير مباشرة، بحيث أصبح التجاوز أساسا تلجأ إليه السلطة لمكاسبها السياسية، فحجم العقارات التي أورثته السلطة الحالية من النظام السابق كبيرة، على الرغم من إقراره لحرية التملك للأفراد، إلا أنّ النظام السابق كان ينتهج نظام اقتصادي اشتراكي مركزي، يعتمد على التخطيط المسبق، وكان يمتلك عناصر الإنتاج كلها، وبكميات كبيرة منها العقارات، وإنّ قيام السلطة الحالية باستغلال هذه العقارات واستثمارها للتنمية غير واضح، بل استأثرت هذه السلطة بحجم كبير منها لصالح الكيانات السياسية المؤلفة لها تحت ذرائع وتسميات صورية من الناحية القانونية، مما أفقدها الحماية القانونية؛ بسبب التعامل غير القانوني معها، وتركها عرضة للغصب والاستيلاء باستمرار. إنّ الوضع السياسي القائم في العراق في الوقت الحاضر مبنيّ على أساس احتكار السلطة لصالح النخبة السياسية المتنفذة داخل الدولة، على نحو يضعف من إرادة الأفراد إلى درجة تغيب دورهم المتمثل في الرفض وتشكيل الرأي العام، إذ يلحظ على الرغم من انتشار ظاهرة التجاوز في أرجاء العراق كله، إلاّ إنّه لا توجد وقفة جماهرية منظمة بصورة تجبر المعنيين من التوقف عندها والخلاصة في هذا السياق هي إنّه وبسبب الأداء السياسي غير السليم، أصبحت عقارات الدولة بمنأى عن الصيانة، وتفتقر إلى الحرمة، إلى درجة بلغت حدّ عجز الإدارات المحلية عن معالجتها، على الرغم من وجود تشريعات خاصة تحمي عقارات الدولة من التجاوز علهها، وتحاسب المتجاوزين، فضلا عن التشديد على مسؤولية رؤساء الوحدات الإدارية على عدم التواطؤ مع المتجاوزين، وعدم صرف النظر عن التجاوز كقرار مجلس قيادة الثورة المنحل المرقم 1111 في 1919/9/10 الذي يعاقب رئيس الوحدة الإدارية ومدير البلدية كل بحسب

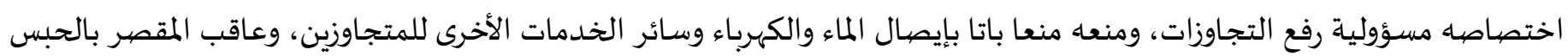
مدة لا تقل عن ستة أشهر ولا تزيد عن ثلاث سنوات، وكذا الحال مع القرار عه السنة ا ـ. . ، الذي بموجبه تشكلت لجنة فرعية برئاسة رئيس الوحدة الإدارية وعضوية ممثل عن المالية والزراعة والبلدية والتسجيل العقاري، تقوم بمهمة إزالة التجاوزات، وإلزام المتجاوز بتسديد نفقة إزالة التجاوز، وتسديد لأجر المثل وقيمة الأضرار الناجمة عنه، وفرض القرار عقوبة على المتجاوز بالحبس مدة لا تقل عن 7 أشهر ولا

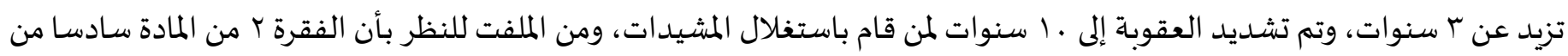

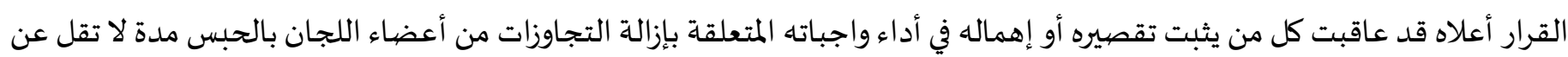
7 اشهر ولا تزيد عن ץ سنوات، وقد شـد مجلس الوزراء على الوزارات وأمانة بغداد برفح التجاوزات الحاصلة على الأراضي والعقارات العائدة

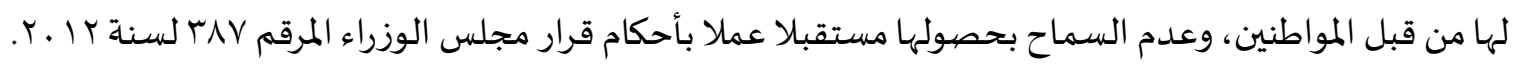




$$
\text { المطلب الثاني }
$$

\section{الأسباب القانونية التي تؤدي إلى التجاوزعلى عقارات الدولة}

لم يكن المشرع العراقي في عدد من تشريعاته موفقاً في الحفاظ على قدسية المصلحة العامة، فهناك عدد من الثغرات في التشريعات البلدية التي أهدرت بعض النصوص الصادرة في حق المجتمع في الاقتصاص من الجاني، وذلك بإقراره التعويض العيني أو المالي للمتجاوز أو تمليكه العقار محل التجاوز، مما شَجع على التمادي بإنتهاك حرمة الأملاك العامة، فضلا عن وجود تناقض في بعض التشريعات الصادرة فيما بينها، فبعض النصوص تشـدد على إزالة التجاوزات، ويعاقب المتجاوز والموظف المتهاون في إزالته، وبعضها الآخر يأمر بالتريث وتعويض المتجاوز، وهذا ما أربك عمل الدوائر البلدياة.

كما كشف بحثنا عن وجود ثغرات عديدة في التشريعات النافذة ساهمت في إضعاف دور نصوص الحماية إلى الحد الذي عرقل عمل الجهات المكلفة بإزالة التجاوزات، وقيّد صلاحياتها، وأكبر هذه العراقيل دستور العراق لعام ه ... ، الذي تسبب في عدد من نصوصها في سحب أهم الصلاحيات الفاعلة المخولة لأمين بغداد ورؤساء الوحدات الإدارية في حجز المخالف لأحكام الحماية، وحصرها بيد القضاة

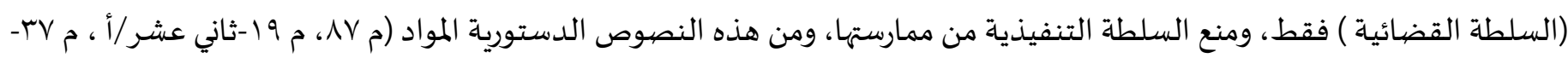
أولا/ب)، وقد تضمنت بعض النصوص القانونية الصادرة قبل نفاذ دستور 0 . . ب تخويل عدد من أعضاء السلطة التنفيذية صلاحية قاضي جنح، لغرض إصدار القرارات القضائية بحجز المخالف عملا بالنصوص القانونية، والتي تم إلغاؤها أو تعطيلها بعد نفاذ دستور ه . . ؟، ومنها على سبيل المثال لا الحصر:

1.القرار رقم (00) لسنة بو 199 الذي خول أمين بغداد صلاحية حجز الأشخاص ممن يلحقون أضرارا أو يرتكبون مخالفات

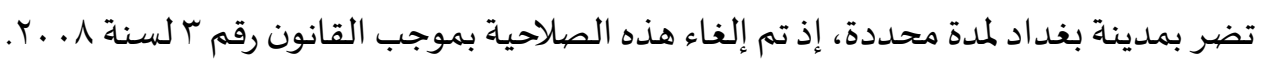

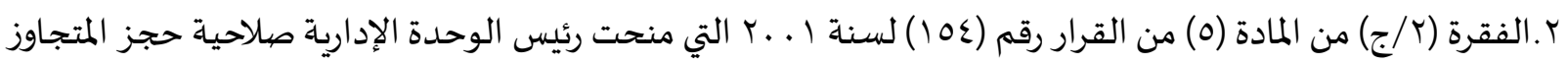

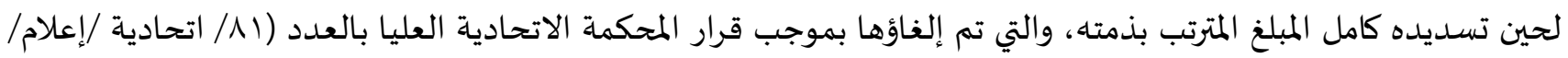

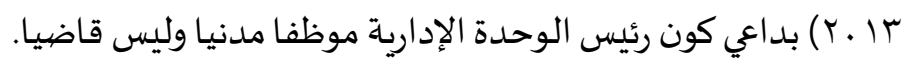
r. المادة (ع 9) من قانون إدارة البلديات رقم 170 السنة ع 197 التي تضمنت الآتي: يعمل أمين بغداد ومدراء البلديات، بصفة

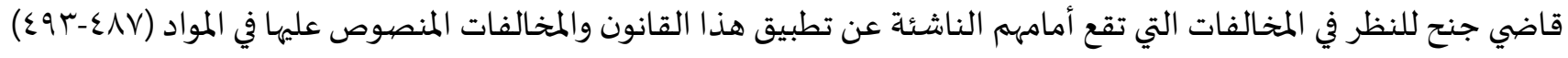
من قانون العقوبات رقم (111) لسنة 1979 الخاصة بالطرق والأماكن المخصصة للمنفعة العامة، إلا أنّ هذه المادة غير معمول

$$
\text { بها حاليا لتعارضها مع الدستور. }
$$

ع.القرار رقم (ع9 ع) لسنة 1919 الخاص بتخويل أمين بغداد صلاحية معالجة تجاوز المركبات على أرصفة الشوارع والمناطق الخضراء في مدينة بغداد، إذ تضمن (البند /أولا) منه تخويل أمين بغد اد صلاحية حجز المركبات الثقيلة والحافلات وسيارات الحمل وسائقها مدة 10 يوما في حالة وقوفها في الأماكن المذكورة، والذي تم تعطيله وإهماله بعد صدور دستور 0 . . ب. 0.قانون تنظيم مناطق تجميع الانقاض رقم (7V) لسنة 1917، إذ تضمنت (المادة ه/أولا) تخويل أمين العاصمة أو من يخوله من مدراء الوحدات ورئيس الوحدة الإدارية، كل ضمن منطقته صلاحية قاضي جنح؛ لغرض تطبيق أحكام هذا القانون، وأكدت تعليماته بالرقم (1 (1) لسنة 1917 ذلك في ( البند رابعا/ )، الذي أشار إلى تطبيق الأحكام الجزائية الواردة في القانون من

$$
\text { قبل الجهات أعلاه، إلا أنّ هذا النص معطل أيضيا لمخالفته للدستور. }
$$

كما أنّ عدم ثبات موقف المشرع العراقي من المتجاوزين يعد ظاهرة غير مرضية، فتارةً يُجَرِّم فعل المتجاوز، وتارةً أخرى يميزه عن الآخرين، بمنح المتجاوز قطعة سكنية، أو تمليكه محل التجاوز، أو تعويضها بمبلغ مالي، كما يلحظ توجه بعض التشريعات الصادرة إبان 
أحداث عام ץ . . r نحو إضعاف سلطة الدولة ككل والسلطة التنفيذية بشكل خاص، وتغليب مصلحة بعض الفئات على حساب مصلحة المجتمع، وذلك بتمرير التشريعات القانونية والتوجههات الرسمية المُهدرة للحق العام، فغياب سلطة القانون وعجز الجهات الحكومية ذات العلاقة عن ايقاف التجاوزات والحد من انتشارها، بل على العكس فقد صدرت مجموعة من القوانين كانت لصالح المتجاوزين، وشجعت على زيادة التجاوزات عن طريق تمليك المتجاوزين.

ونرى أنّ تمليك العقارات المتجاوز عليها للمتجاوزين هو من أهم أسباب عدم السيطرة على التجاوزات، فهذا الإجراء أي التمليك يترتب عليه تشجيع الأفراد على التجاوزات، إذ ليس هناك مبرر من قيام الدولة بتحويل يد الغاصب إلى يد المالك بسبب التمليك. فالمسكن من حاجات الإنسان الأساسية، وإنّ توفيره من المعضلات التي يواجهها العالم، وتصل أزمة المسكن إلى حد المعاناة في أغلب البلدان، والعراق من الدول التي كانت ولاتزال تعاني أزمة سكن، فلأغراض إنسانية قد يقضي المشرع وفي مناسبات متكررة بتمليك العقارات مححل التجاوز على المتجاوزين، الأمر الذي ينتج عنه مساوئ عدة، منها: التشجيع على التجاوز كما سبق القول، وإهدار المال العام على اعتبار أنّ التمليك إما أنْ يكون بشكل مجاني أو ببدل رمزي، وكانت الرسوم و الضرائب غير متناسبة مع الفائدة التي كان يجنيها المتجاوز من الاستغلال أو التصرف بالمساحة المتجاوز علهها، فضلا عمّا تقدم فإنْ إيصال الخدمات إلى مناطق التجاوز قد كلف الدولة مبالغ طائلة جدا.

توجد قوانين وقرارات عدّة صدرت من قبل الحكومتين الاتحادية والإقليم تخص تمليك العقارات المتجاوزة عليها، منها:

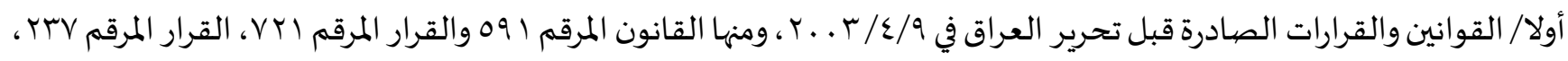

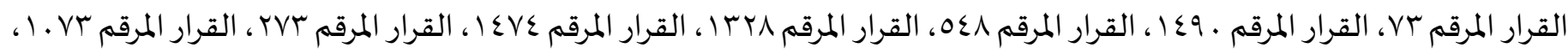

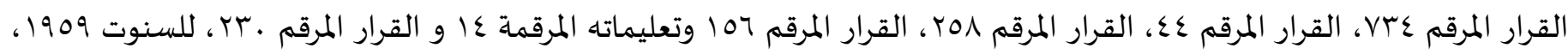

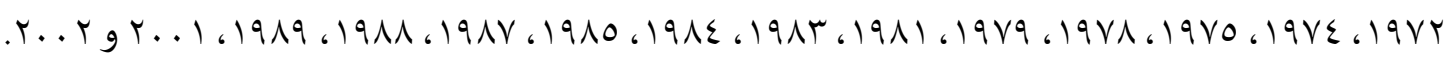

ثانيا/ قرار مجلس الوزراء رقم (.عـ) لسنة م . . ا المتضمن" الإيعاز بصرف مبلغ مالي للمتجاوزين على عقارات الدولة تتراوح بين (1 -

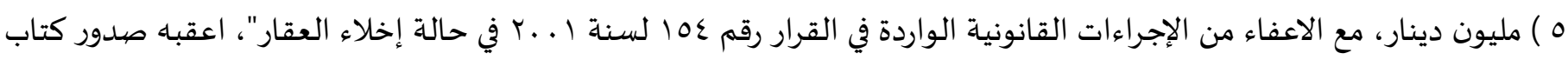

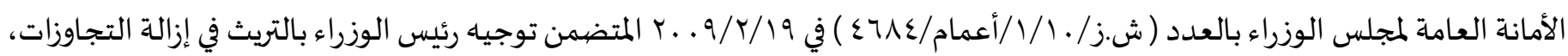

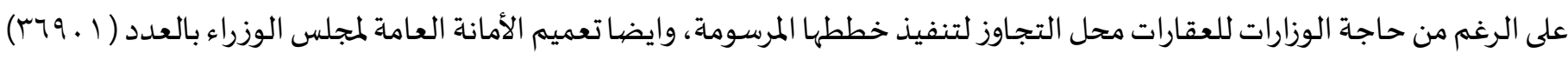

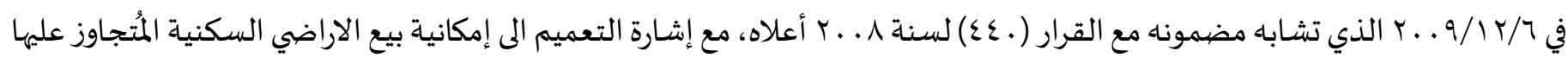

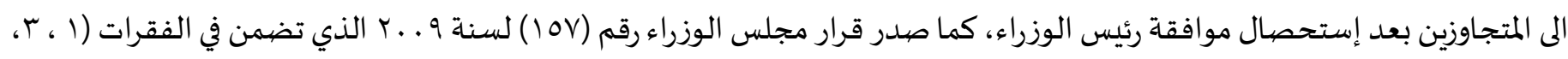
ع) منه إزالة التجاوزات عن بعض أنواع أراضي الدولة مع النظر في مساعدة المتجاوز، فضلا عن التريث في رفع التجاوزات على أراضي الدولة

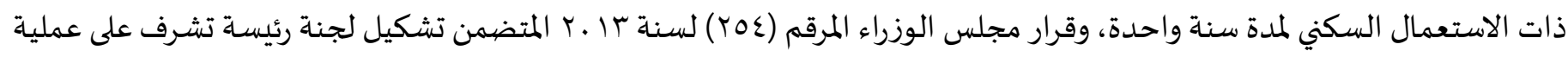
إفراز الأراضي لغرض توزيعها على الفقراء- من سكنة العشوائيات حصراً وتحديد المشمولين وآلية التوزيع.

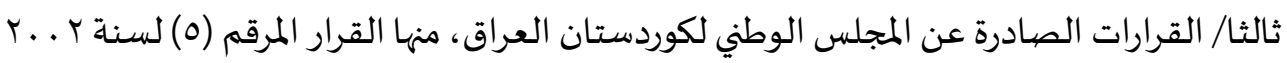
ينص هذا القرار في الفقرة ثانيا منه على أنّ للبلديات تمليك الأراضي المملوكة للإقليم أو للدولة، وحق التصرف فيها للأشخاص، والتي تقع داخل المناطق السكنية حسب التصاميم الأسـاسية، وبأسعار مناسبة للأشخاص الذين أنشأوا تجاوزا أبنية أو دور للسكن عليها قبل

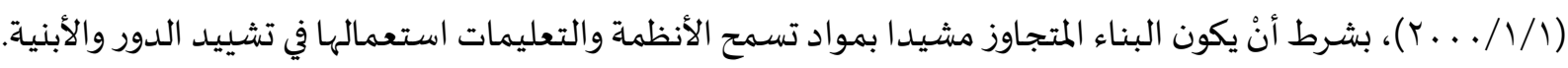
كما جاء في الفقرة الثالثة من القرار أنْ يقدم المتجاوز أو ورثته الشرعيون طلب التمليك إلى البلدية المعنية في مركز العقار خلال مدة سنة واحدة من نفاذ هذا القرار، أما إذا لم يقدم المتجاوز طلب التمليك أو لم يسدد البدل والمصصاريف الأخرى خلال المدة المحددة دون عذر 
مشروع، فيسقط حقه في التمليك، وتسجل المشيدات باسم البلدية ارضاً وبناءا، وللبلدية حق التصرف بها حسب قانون بيع وايجار اموال الدولة.

رابعا/ قانون تمليك الأراضي المتجاوز عليها ضمن حدود البلديات في اقليم كوردستان ـ العراق رقم (r) لسنة (19 ـ ب)

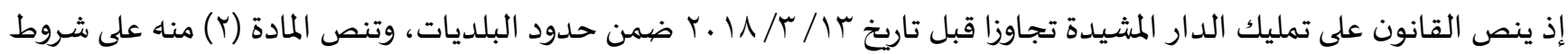

التمليك.

كما جاء في القانون أنْ يقدم طلب تحريري من قبل الشخص الذي يسكن فعليا أو ورثته الشرعيون خلال مدة ــ با يوما من نفاذ هذا القانون، أما إذا لم يقدم المتجاوز طلب التمليك، أو لم يسدد البدل والمصاريف الأخرى خلال المدة المحددة دون عذر مشروع، فيسقط حقه في التمليك، وتسجل المشيدات باسم البلدية ارضاً وبناءا، وللبلدية حق التصرف بها حسب قانون بيع وايجار أموال الدولة، كما حدد القانون قيمة الأرض المتجاوز عليها بدار سكنية(المادة ؟). يستشف من نص القانون أنه منح حق التمليك للساكنين الفعليين في الدار، وليس للمتجاوزين؛ لأنه في بعض الحالات المتجاوز يبيع الدار التي شيدها تجاوزا. إنّ جميع هذه القوانين في مضمونها تصب في صالح المتجاوزين، إذن بمراجعة بسيطة لبعض التشريعات العراقية يظهر التناقض الواضح لحلول المشرع العراقي لظاهرة التجاوزات، وعدم ثبات موقفه من المتجاوزين، فتارةً يُجَرِّم فعل المتجاوز، وتارةً أُخرى يميزه عن الآخرين بمنح المتجاوز قطعة سكنية، أو تمليكه محل التجاوز، أو تعويضها بمبلغ مالي. نخلص مما تقدم أنّ القرارات أعلاه وإنْ كانت غايتها معالجة جزء من التجاوزات في العراق، إلا إنّا إتخذت وسيلة خاطئة ومتخبطة في المعالجة، فلم تَسهُم في حماية العقارات من التجاوز علهها، ولم تضع حدا لأزمة السكن المتفاقمة في الوقت ذاته، ونجد أنّ الحل لا يكون من جانب دوائر البلدية فقط، وإنّما من قبل المشرع أيضا، وذلك بتشريع قانون خاص بتوزيع الأراضي والدور السكنية بضوابط محددة ومجردة، تشمل كافة المواطنين على حدٍ سواء تتضمن عددا من النقاط كالعمر، والحالة الإجتماعية، وعدد الأفراد ممن يعيلهم الفرد، والدخل المعاشي، وغيرها من الاعتبارات، مع ضرورة تظافر جهود كافة الأطراف ذات العلاقة لمعالجة كافة الأسباب والمعوقات المحفزة للتجاوز على عقارات الدولة.

كما أنّ ضعف أجهزة الدولة المعنية بإنفاذ القوانين بعد عام r . . r ، ومن ثم انتشار المافيات والعصيابات المسلحة والتنظيمات الإرهابية

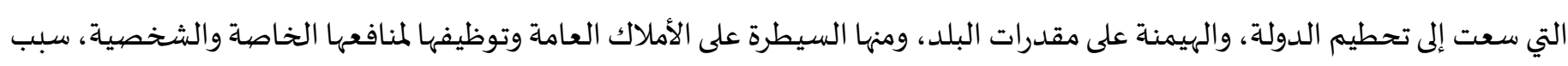
آخر يضاف الى جملة الأسباب التي ذكرناها. هذا وإنّ ضعف الدور الرقابي للجهات الحكومياة، أتاح الفرصة للمتجاوزين في استغلال غياب السلطة وتحقيق المنافع الشخصية، كذلك ضعف الرقابة البلدية بتوجيه التبليغات والاعلام بخطورة تلك الظاهرة على مفاصل المدينة وأضرارها.

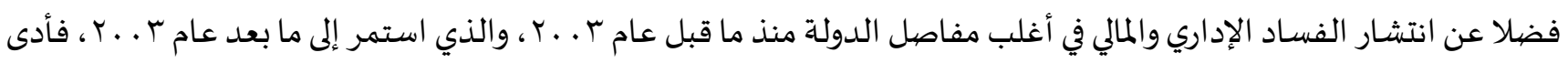
إلى عدم اتخاذ قرارات رادعة ضد المتجاوزين؛ بسبب الفساد الإداري، مما أدى إلى عدم تنفيذ القوانين الصادرة بحق المتجاوزين، وامتناع القضاء عن إزالة التجاوزات وتطبيق أحكام القوانين المذكورة آنفا، والنافذة المفعول بحجة أنّ أمر إزالة التجاوزات منوط بالإدارة، متناسيا بأنّ القرار عها لسنة ا ـ ـ ق قد منح للقضاء صلاحيات جزائية، وكذلك منح الجهة صاحبة العقار حق تحريك شكوى جزائية (لتوفر عنصر

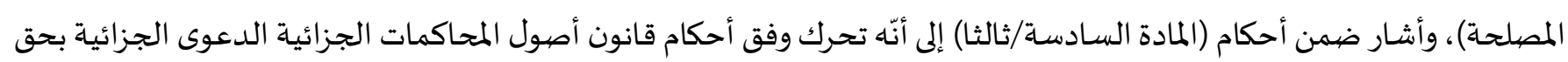
المنصوص عليهم في الفقرتين ا و Y من هذا البند، بطلب من الجهة المالكة أو التي تقع العقارات المتجاوز عليها تحت إدارهها أو إشرافها أو

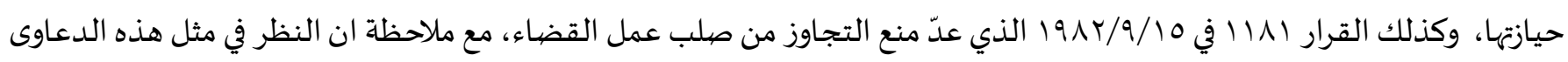


جزائيا ليست ضمن الصلاحيات الجزائية الممنوحة لرؤساء الوحدات الإدارية وفق عددٍ من القوانين، فضلا عن تقييد الإدارة بعد عام r . . r بعدم ممارسة دور القضياء انطلاقا من مبدأ الفصل بين السلطات، وحسب التعاميم التي ترد من مجلس القضياء الأعلى، وكذلك اتجاه المحكمة الاتحادية حين نظرها في بعض من هذه الدعاوى.

\section{المطلب الثالث}

\section{الأسباب الاقتصيادية والاجتماعية}

نقسم هذا المطلب الى فقرتين، نبحث في الفقرة الأولى الأسباب الاقتصادية وفي الفقرة الثانية نبحث في الأسباب الاجتماعية للتجاوز على عقارات الدولة.

\section{اولا: الأسباب الاقتصبادية}

بعد أنْ كان سبب التجاوز على عقارات الدولة مجرد حاجة للسكن تحول في الوقت الحاضر إلى المتاجرة، إذ لم يعد يمارس من قبل الفقراء ومحدودي الدخل فحسب، بل تتحكم فياه جماعات متنوعة ترتزق منها، كنتيجة طبيعية لترسيخ النظام الإقطاعي وحرمان الفلاحين من حقوقهم وتدهور حالتهم الاقتصادياة، وظهور البطالة بشكل كبير بين الطبقات الأخرى في الريف والنواحي والأقضية، فقدْ فقدَ هؤلاء مصددر الرزق مما اضطرهم إلى هجرة المدن الرئيسـة، إذ إنّ المعامل والمصانع والمشـاريع المتواضعة قد أقيمت في المدن الكبيرة مما زاد من هجرة هؤلاء العاطلين إلى المدن للعمل في تلك المشاريع للرزق. ولما كانوا عاجزين عن تأمين المساكن لهم ولعوائلهم في مناطق أعمالهم، فقد قاموا بتشييد المساكن المؤقتة على أراضي الدولة في

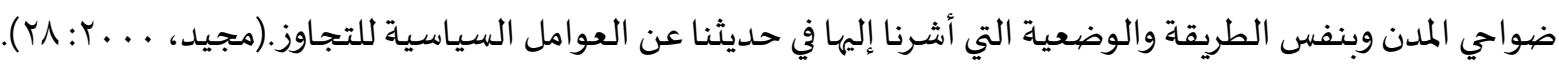
ومن الأسباب الاقتصادية الأخرى ما يتمثل بالفقر وتفاقم الأزمات الأقتصادية، وارتفاع معدلات البطالة، وعوامل اقتصادية كامنة في السعي من أجل تحقيق أعلى معدلات الأرباح عن طريق التجارة بالأراضي التي وضعت عليها اليد بغير ثمن.

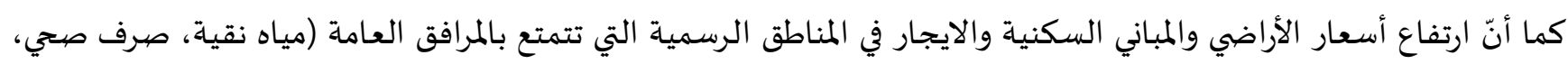
كهرباء)، إذ إنّ الأشخاص الذين لديهم الأراضي قاموا ببيع أراضيهه أو دورهم السكنية وقاموا بشراء أرض في مناطق التجاوزات بأقل سعر وبمساحة أوسع.

وتوافر المواد الإنشائية المحلية(حجر، الجص، الرمل والحصى،) وانخفاض أسعارها، وتوفر الأيدي العاملة الرخيصة، أدى إلى إنخفاض كلف إنشاء الوحدات العمرانية السكنية غير الأصولية، مما شجع هذا على البناء ضمن الأراضي التي تمتلكها الدولة. يضاف الى ما تقدم قلة الدخل لأغلب السكان، الذي دفع إلى تجاوز بعض السكان على الأماكن الفارغة أو فرز مالكي البساتين والأراضي لهي لهي الزراعياة لأراضيهم، وتخصيصها لقطع سكنية، وبيعها بأسعار مناسبة، وبأحجام مختلفة.

وضعف الحالة الاقتصادية لأغلب المواطنين بسبب سياسة الحكومات التي سبقت عام ؟ . . r ، ومنها الحروب المدمرة التي دخل فيها العراق، وكذلك الحصار الجائر الذي عانى منه المواطن فقط دون الحكومات التي كانت تتولى إدارة البلد، وبعد ذلك الاحتلال وظروفه التي نعاني من عقابيلها الآن، وارتفاع معدل البطالة في عموم المدن العراقية، وغياب دور الدولة في توفير فرص اقتصادية لمواطنيها، كذلك ارتفاع المستوى المعاشي لشريحة الموظفين بعد عام r. . r، ورغبة هؤلاء في امتلاك وحدات سكنية داخل حدود المدينة، كل هذه الأمور أسباب تضاف إلى الأسباب السابقة الذكر.

كما أنّ تعاظم الإنفاق العسكري، وتراجع دور الدولة في الاستثمار، وتوجهها منذ عام .9191 ولحد الآن نحو زيادة النفقات العسكرية، التي أدت إلى استنزاف العوائد المالية للدولة العراقية، مما ترتب عليه حرمان بقية القطاعات الاقتصادية من التخصيصات المالية لتطويرها، 
ومن ضمنها قطاعي السكن والخدمات، وعدم الموازنة الدقيقة بين الحقوق والواجبات، نجم عنها ترجيح المنفعة الفردية الخاصة على المصلحة الاجتماعية العليا، فكانت سببا من أسباب التجاوز على عقارات الدولة.

\section{ثانيا: الأسباب الاجتماعية}

في أوائل سنة عه 19 بدأت حركة عمران واسعة في العراق شملت أنحاء القطر كافة، مما أدى إلى توسيع حدود المدن، ويعني ذلك دخول الصرائف ضمن حدود البلديات، وحيث كان وجودها عاملا معرقلا في نمو المدن، وتنفيذ مشاريع خطط التنمية التي بوشر بها، وكان في الوقت نفسه مشوها لمنظر المدن، ومبعثا لتلوث البيئة، فقد فكرت الدولة في نقل هؤلاء إلى أماكن أخرى، وفعلا تم تشييد مجتمعات سكنية صحية ودائمية لهم، فتم تشييد مدينتين في بغداد إحداهما في شرقي بغداد باسم (مدينة الثورة) والأخرى في الشمال الغربي باسم (مدينة الشعلة)، ضمتا عشرات الآلف من الوحدات السكنية، زودت بالخدمات الضرورية كافة و وزعت على أصحاب الصرائف من الفلاحين السابقين، والعمال وذوي دخل المحدود.

كما تم تهيئة الأراضي السكنية لتوزيعها مجانا على الذين لا يملكون المساكن، على أنْ يقوموا بتسييدها في ثلاث سنوات من تاريخ

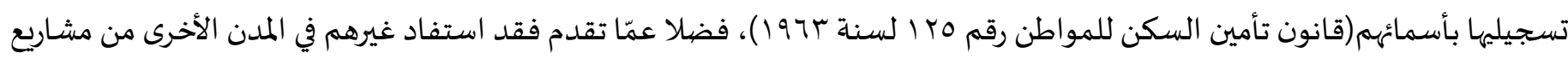
الإسكان التي قامت بها الدولة، ومنع تشييد الصرائف بعد ذلك، والدولة وإنْ استعادت بذلك سيطرتها الفعلية على قسم من الأراضي المتجاوز عليها، إلّا إنّ التجاوز ظل قائما في أقسام أخرى منها. ومع كل ذلك فإنّ تلك المشـاريع لم تواكب نمو عدد أفراد العائلة والتضخم السكاني الذي شهده العراق، كما أنّ انخراط الكثير من أفراد هذه العوائل في صفوف القوات المسلحة، وتقلد بعضهم الوظائف العامة في الدولة، واشتغال عدد كبير منهم بالأعمال التجارية والصناعية قد غير وضعهم الاجتماعي، وأحدث تحسنا في مستوى معيشتهم، مما أدى إلى طموح كل فرد من أفراد العائلة الواحدة إلى الاستقلال عن عائلته وامتلاك مسكن خاص باه بما عرف بحالة الانشطار العائلي. إنّ التقدم الحضياري والعمراني في العراق - بوجه العام- ونمو المدن وامتدادها - بوجاه خاص- قد أديا إلى ارتفاع أسعار العقارات ارتفاعا

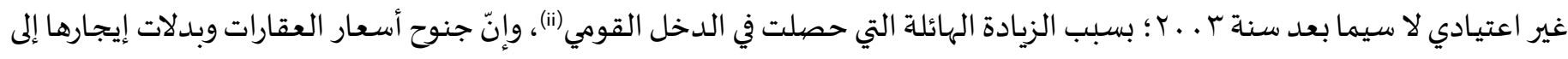
الارتفاع بشكل غير طبيعي قد حال دون تحقيق رغبة العوائل المعدومة في تملك المساكن؛ لأههم من ذوي الدخل المحدود، فلجؤوا تحقيقا لذلك إلى التجاوز على عقارات الدولة في ضواحي المدن، وقاموا بتشييد دور السكن عليها على شكل مجمعات سكنية ثابتة، وبدلا عن منعهم من التجاوز تم إضافة عبء كثير على الدولة لتأمين الخدمات اللازمة مثل الماء والكهرباء ووسائط النقل العمومياة، التي كانت سببا لاستقرارهم

وجدير بالذكر أنّ الزيادة السكانية الكبيرة التي حدثت في معظم المدن العراقية، وتدهور الوضع الأمني في عموم مناطق وسط العراق

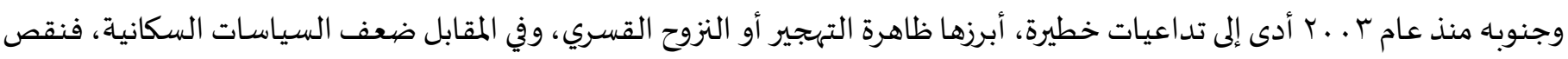
الرصيد السكني الذي يلازمه الارتفاع المتزايد لأعداد السكان داخل المدن العراقية، أي قلة المتوفر من وحدات سكنية ومحلات، ولما كان الإسكان بطبيعته بطيء التفاعل مع التغييرات التي تحدث في الهيكل الديمغرافي للمجتمع، لذلك حدث عجز تراكمي في الوحدات السكنية، يقابله نسبة عالية من الاندثار في الرصيد السكني، كذلك قلة مشاريع الإسكان، فالنقص في الوحدات السكنية مع الزيادة الانفجارية في عدد

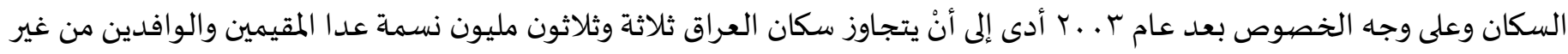
العراقيين، وهؤلاء يشكلون عبءً إضافيا؛ لأهم بحاجة إلى سكن سواء السكن مؤقتا أو دائميا. 
فغياب السياسـة الإسكانية الاستراتيجية الصحيحة هي إحدى أسباب التجاوزات في الوقت الذي عصفت بالبلاد موجات من الهجرة والتغيير الديمغرافي، مما حدا بالكثير إلى ترك مناطقهم والنزوح إلى أماكن أخرى، إذن هناك سببان: الأول، تزايد معدلات النمو السكاني، والآخر، الهجرة والنزوح إليها. فالهجرة القسرية، أي الهجرة الداخلية الناشئة عن الاضطراب السياسي والأمني والاجتماعي والاقتصادي، كالحرب ضد الإرهاب، الاقتتال الطائفي والعشائري، أو الهجرة من المناطق التي لاتوجد فهها فرص عمل جيدة إلى المناطق التي تتمتع بكثرة فرص العمل وتنوعها، وكذلك الهجرة من الريف إلى المدينة، كذلك نتائج الحروب والأزمات السياسية التي ألحقت الضرر بممتلكات المواطنين من وحدات سكنية أو أو اله أراضي أو محلات تجارية، وعدم استقرار الوضع الأمني، سبب آخر يؤدي إلى التجاوزات. هذا ومن الأسباب الاخرى سوء إدارة الدوائر الحكومية، وتقصيرها في حقوق الناس، مما يخلق أحيانا رد فعل عند المواطن، يدفعها إلى لي

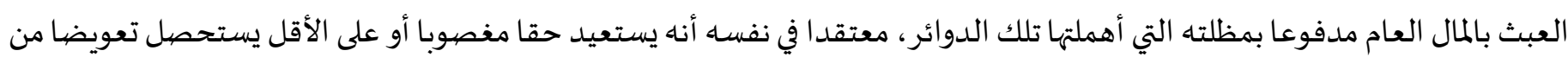
خلال منفعة شخصية. كذلك قلة الوعي لدى المواطن، وجهل المواطنين بأهمية مخطط المدينة (التصميم الأساس)، مما يشعر المتجاوزين أنّه ليس ثمة إجراءات عقابية على من تجاوز، كذلك تأخر المساءلة بسبب المحسوبية، بل بعض الأحيان هناك مكافأة تنتظره، وهي تمليكاه ما تجاوز عليه في أماكن أخرى وبأوقات سـابقة. وجدير بالذكر أنه أخذت أزمة تلو أخرى تعصف بالبلاد، فقبل أنْ تتم معالجة أزمة ما تأتي أخرى أقوى منها لتجعل البلاد في تخبط وفساد إداري وقضائي وتشريعي، فالسلطات باتت وكأن لا دور لها في معالجة هذا الملف المهم، فالتجاوزات على أراضي الدولة من قبل المواطنين والمؤسسات تزداد يوما بعد آخر، دون أنْ تتجرأ الإدارة على إزالتها. لذا تتحمل السلطات الثلاث (التنفيذية والقضائية والتشريعية) مسؤولية ضياع أملاك الدولة لاسيما أنّ معظم المتجاوزين لا يدفعهم عنصر الحاجة الماسـة، ويبقى الشخص الذي يحب تطبيق القانون والعدالة خاسرا، وكأنْ الامر مكافأة لمن يخرق القانون. خلاصة القول إنّ وراء ظاهرة التجاوز على عقارات الدولة أسباب نلخصها في الفقرات الآتية: اولا/ غياب توجاء السلطات المعنية الرسمي الإجرائي الواضح والحازم تجاه هذه الظاهرة، على الرغم من وجود تشريعات خاصة بمكافحة التجاوزات سواء قبل أو بعد العام 2003. ثانيا/ ضعف رقابة الجهات الحكومية وتهاونها الواضح في المتابعة وإيقاف هذه الظاهرة مما شجع المتجاوزين بشكل لافت، إمّا على الاستمرار في تجاوزهم أو بناء وحدات سكنية عشوائية جديدة. ثالثا/انعكاسات ارتفاع نسبة الفقر في العراق بشكل ملحوظ على تنامي نسبة العشوائيات، فتردي الأوضاع الاقتصادية لدى المواطنين (ضعف الحالة الاقتصادية أدّى بالمواطنين إلى شراء أراضي في أطراف المدينة، والتي لا تزال غير منظمة). رابعا/ ارتفاع قيمة العقارات وبدلات الايجار بشكل كبير لاسيما في المدن الكبيرة التي تحتضن أكبر نسبة للعشوائيات، والارتفاع في اسعار الأراضي وما تبعاه من عدم مقدرة بعض الفئات الشعبية على شراء الأراضي والبناء عليها. خامسا/ الهجرة المستمرة وغير المبرمجة من الريف إلى المدينة لدواع اقتصادية، واجتماعية مختلفة، وأيضا الهجرات الاضطرارية نتيجة الحروب والكوارث.

سادسا/ الظروف الأمنية التي يمر بها العراق ساهمت بشكل كبير في زيادة ظاهرة العشوائيات وما يخلف ذلك من نزوح الملايين ممن يتركز عدد كبير منهم في المدن وأطرافها، واضطرار نسبة منهم الى السكن على الأملاك العامة، أو مساكن متواضعة من (البلوك) أو حتى من 
سابعا/ تخوف بعض الجهات الحكومية من مكافحة ظاهرة العشوائيات لتحول بعض هذه العشوائيات إلى تجمعات ذات قوة مسندة من جهات متعددة قد تشكل خطرا على المتصدين لهذه الظاهرة، ووجود بعض التدخلات من جهات سياسية واجتماعية تمنع أو تعيق جهود الحد منها، معللين تدخلاتهم باعتبارات اقتصادية وإنسانية.

ثامنا/ مد بعض المناطق بالخدمات الأساسية (الكهرباء والماء، والصرف الصبح) ممّا ولّد قناعة لدى ساكني هذه المناطق والمناطق الأخرى بأنّ امتداد الخدمات لهم يعني أههم أصبحوا (واقع حال) مفروض على الدولة، ولا يمكن إخلاء مناطقهم مستقبلا. تاسعا/ حب التملك لدى بعض الأشخاص يقابله الطمع في أراضي الدولة، فضلا عن قيام بعضهه بالمتاجرة عن طريق إفراز قطع الأراضي وبيعها بمبالغ كبيرة.

\section{الخاتمـة:}

في أهم الاستنتاجات والتوصيات:

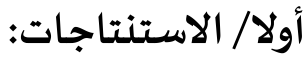

/ / إنّ التجاوز على عقارات الدولة يعني قيام شخص بوضع اليد على عقارات مملوكة للدولة لغرض استعمالها أو استغلالها دون مسوغ قانوني.

ك/ إنّ التجاوز على عقارات الدولة وجد منذ القدم وبأنماط ودوافع مختلفة، ويتوسع كلما تهاونت السلطة في مواجهته. r/ إنّ الأسباب التي تؤدي إلى التجاوز على عقارات الدولة متعددة، منها سياسية بدرجة أساس، وتليها أسباب قانونية، واقتصادية وإجتماعياة.

ع / على الرغم من وجود تشريعات وقرارات عديدة تخص منع التجاوز على عقارات الدولة أو إزالته، إلا أنه لايزال التجاوز بكثرة، إذ يلحظ تقاعس السلطة التنفيذية في العمل على الحد منه. / / إنّ التعامل اللامسؤول من قبل السلطة السياسية في العراق وإقليم كوردستان مع ممتلكات الدولة بصورة عامة والعقارات المملوكة للدولة على وجه الخصوص نتج عنه استباحتها وتجريدها من الحماية الدستورية والتشريعية التي كانت تتمتع بها قبل سقوط

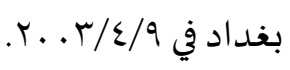

7/ إنّ مخاطر التجاوز على عقارات الدولة كبيرة، إذ تتمثل في إضعاف سيادة القانون وهيبة الدولة، فضلا عن إهدار المال العام والخروج عن مبدأ المسـاواة بين المواطنين، وإضعاف قطاعات اقتصادية رئيساة، وتشويه وعرقلة المخططات العمرانية وتلوث

V/ إنّ المشرعَين العراقي والكوردستاني يجانبان الصواب في كثير من الأوقات عندما يقدمان على إعفاء المتجاوزين من المسؤولية، وذلك

$$
\text { بإصدار قوانين وقرارات العفو عن المتجاوزين، أو بتمليك العقارات محل التجاوز عليهم. }
$$

/ لم يقم المشرع العراقي إلى الآن بتشريع قانون لحماية أملاك الدولة على وفق نص المادة (VV/ثانيا) من الدستور العراقي الدائم، إذ

$$
\text { بقيت القواعد القانونية المعنية بحماية الأموال تلك متبعثرة في تشريعات متعددة يصعب الاعام بها. }
$$

9/ تتحمل الجهات الأمنية واللجان المعنية بمنع التجاوزات على عقارات الدولة وإزالتها مسؤولية ازدياد التجاوزات على عقارات الدولة

$$
\text { بمختلف أنماطها، إذ إنّ الواقع أثبت قصورهما في حماية عقارات الدولة من التعدي والتجاوز عليها. }
$$

• ا/يعد تشريع قانون منع وإزالة التجاوز على أراضي الدولة في إقليم كوردستان-العراق خطوة إيجابية لمكافحة ظاهرة التجاوزات

$$
\text { مقارنة بالسلطة الاتحادية التي تفتقر لمثل هذا القانون في الوقت الحالي.. }
$$


/ / نقترح تعديل مصطلح الأموال العامة بمصطلح أموال الدولة أينما ورد في القوانين التي تتناول حماية هذه الأموال، وذلك للدلالة على حماية أموال الدولة العامة والخاصة على حد سواء، هذا من جانب، ومن جانب آخر ليتمثل بمنع أي تأويل بهذا الصدد من شأنه أنْ يضيق نطاق أموال الدولة الخاضعة للحماية. r/ نرى ضرورة أنْ يفرد المشرع قانونا خاصا يحدد بموجبه الحماية القانونية لعقارات الدولة، سواء كانت هذه الحماية مدنية، أو جنائياة، تحدد بموجبه نصوص عامة تنطوي على حماية تلك العقارات، فمن الضروري توحيد النصوص التي تقرر الحماية لعقارات الدولة، فنقترح في هذا المجال تشريع قانون حماية أموال الدولة إستناداً إلى المادة (Y/TV) من دستور عام ه . . ، ليلم شتات نصوص الحماية القانونية المتفرقة، مع التشديد على إلغاء كافة النصوص المتناقضاة والنصوص القانونية المُغَلِبة للمصلحة الخاصة على حساب المصلحة العامة، كما ينبغي أنْ يتضمن القانون المقترح كافة إجراءات إزالة التجاوز، وقواعدوأسس المس

$$
\text { تقدير التعويض؛ ليكون المرجع في ذلك دون إيرادها في تشريعات وقرارات متفرقة. }
$$

r/ نقترح على المشرع العراقي أنْ يعالج موضوع التجاوز بشكل أكثر جدية لأهميته ولما يشكله من خطورة على أمن الدولة واستقرارها، وإنّ إجراءات إزالة التجاوز على عقارات الدولة في العراق والتي عالجتها عدة تشريعات وقرارات قد تفاوتت بصرامة الإجراءات وقوتها، لذا ندعو المشرع العراقي إلى إعادة النظر في تلك الإجراءات، بحيث تحقق الغرض منها بإزالة تلك التجاوزات، وعدم العود

ع / ندعو إلى ضرورة تأسيس محاكم خاصة بقضايا التجاوزات على عقارات الدولة في العراق، كما فعل المشرع الكردستاني في قانون

$$
\text { منع وازالة التجاوز على أراضي الدولة. }
$$

0 / نقترح على المشرع العراقي منع حالة تمليك أراضي الدولة للمتجاوز، مع إقرار معالجات أخرى لمشاكل السكن أو المشاكل الأخرى، وأنْ يكون النص على هذا النحو: (لا يجوز تمليك أراضي الدولة المتجاوز عليها، سواء أكانت أراضي عامة أم خاصهة، ويعد أي تصرف 


\title{
Reasons for Encroachment on State Real Estate ‘and its Downsides (Analytical Study)
}

\section{Rekan Farhan Salih}

Department of Law, Faculty of Humanities and Social Sciences, University of Koya, Koya, Kurdistan Region, Iraq.

E-mail: Rekan.farhan@koyauniversity.org

\section{Rebaz Ardalan Bakr}

Department of Law, Faculty of Humanities and Social Sciences, University of Koya, Koya, Kurdistan Region, Iraq.

E-mail: rebaz.alhawezy@koyauniversity.org

\begin{abstract}
:
The phenomenon of abuses on state real estate has exceeded all expectations 'due to its increase for political 'legal 'economic and social reasons 'as the state's real estate has not been spared from encroachment on it in recent times a and the abuse has formed different patterns * the motive of which is according to its status the interests of the transgressors 'which resulted in the time At the present time and in particular after the fall of the defunct Baathist regime ، the state's property was liberated ras there was no strong deterrent to it.

Despite the issuance of strict laws and decisions criminalizing and forbidding encroachment on state real estate and with the presence of the executive and judicial authorities concerned with their application and implementation the phenomenon of transgression is on the rise 'which results in many negatives and on many levels the most important of which is wasting public money and non-compliance and respect for the law 'As well as the demographic change of cities.

The research dealt with these issues as an attempt to contribute to presenting the problem of abuse sand to provide solutions to it 'In order to understand the aspects of the research sthe study was divided into two sections 'In the first section 'we discuss the concept of encroachment on state real estate 'As for the second topic 'we are devoted to talking about the causes of encroachment on state real estate 'We also conclude the research by mentioning the most important conclusions and recommendations.
\end{abstract}

Keywords: Excese, Real Estates, Reasons. 


$$
\begin{aligned}
& \text { ابن منظور، جمال الدين ابو الفضل محمد بن مكرم، (1907)، لسان العرب، المجلد التاسع، بيروت، دار صادر. } \\
& \text { ابو زيد، د.محمد عبدالحميد، (19V1)، حماية المال العام، القاهرة، دار الهضضة العببية. } \\
& \text { ابو سعد، د.محمد شتا، (ع/911)، اصول المسؤولية التقصيرية في قانون المعاملات المدنية الأسلامي السوداني، ط ا. } \\
& \text { البرزنجي، د. عصام عبد الوهاب، (r991)، مبادئ وأحكام القانون الإداري، بغداد، مديرية دار الكتب للطباعة والنشر. } \\
& \text { بعلي و أبو العلا، محمد الصغير و يسرى، (r. . ب)، المالية العامة، النفقات العامة، الإيرادات العامة، الميزانية العامة، دار العلوم للنشر و التوزيع. } \\
& \text { جماعة من اللغويين العرب، (1911)، المعجم العربي الأساسي، المنظمة العربية للتربية والثقافة والعلوم، تونس. } \\
& \text { السلامي، مهدي ياسين، (ب991)، مبادئ وأحكام القانون الإداري، بغداد، مديرية دار الكتب للطباعة والنشر. }
\end{aligned}
$$

السنهوري، د. عبد الرزاق احمد، (1971)، الوسيط في شحح القانون المدني الجديد، نظرية الالتزام بوجه عام الإثبات، آثار الالتزام، القاهرة، دار النهضة العربية. السنهوري، د.عبد الرزاق احمد، (ع ـ.ب)، الوسيط في شرح القانون المدني، جـ - حق الملكية، تنقيح المستشار احمد مدحت المراغي، الاسكندرية، الناشر منشأة المعارف.

شيحا، د. إبراهيم عبد العزيز، (بلا سنة طبح)، الوسيط في أموال الدولة العامة والخاصة، الإسكندرية، دار المطبوعات الجامعية. الطماوي، د. سليمان محمد، (ז个199)، الوجيز في القانون الإداري، القاهرة، دار الفكر العربي. عبداللطيف، د. عبود، (19v0)، دراسة في الحقوق العينية الاصلية، بغداد، مطبعة المعارف.

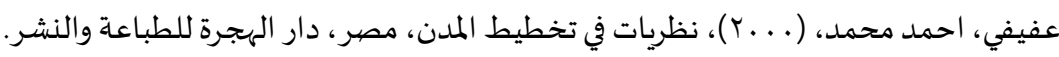
عمر، احمد مختار، (^. . )، معجم اللغة العربية المعصرة، طا، القاهرة. الفياض، د. ابراهيم طه، (بلا تاريخ)، القانون الإداري (نشاط واعمال السلطة الإدارية بين القانون الإداري والمقارن)، مكتبة الفلاح.

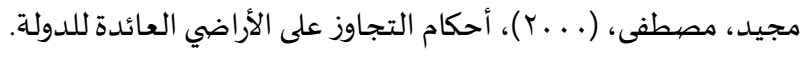
مرسي، د. محمد كامل، (1970)، الأموال، مطبعة الرغائب. معلوف، لويس، (1997)، المنجد في اللغة والأدب والعلوم، ط7، بيروت، المطبعة الكاثوليكية. مهنا، د. محمد فؤاد، (بلا سنة طبع)، مبادئ وأحكام القانون الإداري، بلا دار نشر. الواسطي، د. فاضل شاكر، (19VT)، اقتصبادات المالية العامة، بلا دار نشر.

الاعسم، خليل إبراهيم جبار، (1911)، التجاوزات على الملكيات الأراضي في التشريع العراقي، رسالة ماجستير، غير منشورة، المعهد العالي للتخطيط الحضري والإقليمي، جامعة بغداد. 
حسن، سعدي عبيد، (.999)، تحجيم المدن الكبرى دراسة إستراتيجية لسكان بغداد الكبرى، رسالة ماجستير، غير منشورة، المعهد العالي للتخطيط الحضبري والإقليمي، جامعة بغداد.

العبيدي، حميدة عبيد علوان، (0 . . ) ، المشاكل التخطيطية الناجمة عن توسع مدينة المحمودياة، رسالة ماجستير، غير منشورة، المعهد العالي للتخطيط الحضري والإقليمي، جامعة بغداد.

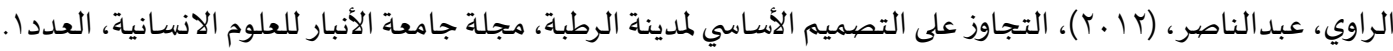
منسى، وليد عبدالله، (V . . r)، مظاهر التعدي الحضري في مدينة الكويت، مجلة دراسات الخليج والجزيرة العربية، العدد؟ ا ، الكويت. الدستور العراقي لسنة ه. . ب.

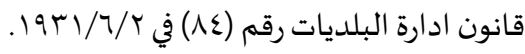
قانون المدني رقم (.ع) لسنة 1901. قانون الاصلاح الزراعي رقم VI السنة . $19 V$. قانون توحيد اصناف أراضي الدولة رقم (rه) لسنة $19 \vee 7$. قانون استغلال الشواطئ رقم (09) لسنة 191V. قانون ادارة بلديات لإقليم كردستان رقم (7) لسنة بـ199. قانون المحافظات غير المنتظمة في اقليم رقم (ابr) لسنة م ـ. ب المعدل. قانون منع وازالة التجاوز على أراضي الدولة في اقليم كردستان ـ العراق رقم (r) لسنة \\ــ. قانون تمليك الأراضي المتجاوز عليها ضمن حدود البلديات في اقليم كرستان ـ العراق رقم (؟) لسنة 19 ـ ؟.

Younan R.، A( 1985) 'open space associate economic faction the physical structure of the met-politer Region of Baghdad ‘Baghdad University ‘Baghdad.

i . تقرير المستح التمهيدي لتجمعات السكن العشوائي لسنة با ـ. ، المعد من قبل الجهاز المركزي للإحصاء/وزارة التخطيط.

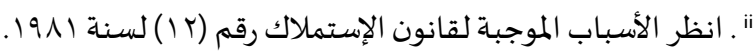

